Research Paper

\title{
IL-15 Generates IFN-Y-producing Cells Reciprocally Expressing Lymphoid-Myeloid Markers during Dendritic Cell Differentiation
}

\author{
Kee Woong Kwon ${ }^{1 *}$, So Jeong Kim ${ }^{1 *}$, Hongmin Kim ${ }^{1}$, Woo Sik Kim ${ }^{1}$, Soon Myung Kang ${ }^{1}$, Eunsol Choi ${ }^{1}$, \\ Sang-Jun Ha ${ }^{3}$, Joo-Heon Yoon ${ }^{2 \bowtie}$, and Sung Jae Shin ${ }^{\bowtie}$ \\ 1. Department of Microbiology, Institute for Immunology and Immunological Disease, Brain Korea 21 PLUS Project for Medical Science, Yonsei University \\ College of Medicine, Seoul, South Korea. \\ 2. The Airway Mucus Institute, and Department of Otorhinolaryngology, Yonsei University College of Medicine, Seoul, South Korea. \\ 3. Department of Biochemistry, College of Life Science \& Biotechnology, Yonsei University, Seoul, South Korea. \\ * These authors contributed equally to the work.
}

$\square$ Corresponding authors: Sung Jae Shin, Department of Microbiology and Institute of Immunology and Immunological Diseases, Yonsei University College of Medicine, Seoul 03722, South Korea. E-mail: sjshin@yuhs.ac, Tel.: (82) 2-2228-1813, Fax: (82) 2-2-392-9310; and Joo-Heon Yoon, The Airway Mucus Institute and Department of Otorhinolaryngology, Yonsei University College of Medicine, Seoul, Korea. E-mail: jhyoon@yuhs.ac, Tel.: (82) 2-2228-3610.

(c) Ivyspring International Publisher. This is an open access article distributed under the terms of the Creative Commons Attribution (CC BY-NC) license (https://creativecommons.org/licenses/by-nc/4.0/). See http://ivyspring.com/terms for full terms and conditions.

Received: 2018.02.26; Accepted: 2018.12.02; Published: 2019.01.01

\begin{abstract}
Recently, interest in IL-15-differentiated cells has increased; however, the phenotypic definition of IL-15-differentiated bone marrow-derived cells (IL-15-DBMCs) is still under debate, particularly the generation of IFN-Y-producing innate cells such as premature NK (pre-mNK) cells, natural killer dendritic cells (NKDCs), interferon-producing killer dendritic cells (IKDCs), and type 1 innate lymphoid cells (ILCIs), all of which are IL-15-dependent. Here, we revisited the immunophenotypic characteristics of IFN-Y-producing IL-15-DBMCs and their functional role in the control of intracellular Mycobacterium tuberculosis (Mtb) infection. When comparing the cytokine levels between bone marrow-derived dendritic cells (BMDCs) and IL-15-DBMCs upon stimulation with various TLR agonists, only the CD $11 c^{\text {int }}$ population of IL-15-DBMCs produced significant levels of IFN- $\gamma$, decreased levels of MHC-II, and increased levels of B220. Neither BMDCs nor IL-15-DBMCs were found to express DX5 or NK1.1, which are representative markers for the NK cell lineage and IKDCs. When the CD11 cintB220+ population of IL-15-DBMCs was enriched, the Thy 1.2+Sca-1+ population showed a marked increase in IFN-y production. In addition, while depletion of the $\mathrm{B} 220^{+}$and Thy $1.2^{+}$populations of IL-15-DBMCs, but not the CD19+ population, inhibited IFN-Y production, enrichment of these cell populations increased IFN-y. Ultimately, co-culture of sorted IFN-Y-producing B220+Thy1.2+ IL-15-DBMCs with Mtb-infected macrophages resulted in control of the intracellular growth of Mtb via the IFN- $\gamma$-nitric oxide axis in a donor cell number-dependent manner. Taken together, the results indicate that IFN-Y-producing IL-15-DBMCs could be redefined as CD $11 \mathrm{c}^{\text {intB220+Thy } 1.2+S c a-1+}$ cells, which phenotypically resemble both IKDCs and ILCIs, and may have therapeutic potential for controlling infectious intracellular bacteria such as Mtb.
\end{abstract}

Key words: IL-15, IFN-ץ, Dendritic cells, B220, Mycobacterium tuberculosis

\section{Introduction}

Interleukin (IL)-15 is a multipotent cytokine with immunoregulatory properties that is produced by various cell types, but it is predominantly expressed by myeloid cells (1). In general, IL-15 serves as a growth factor by promoting the survival and differentiation of lymphoid cells such as T, B, and NK cells. Thus, IL-15 is thought to play an essential role in the development, homeostasis and maintenance of those cell types. In addition, IL-15 also serves multiple functions including regulating the $\mathrm{T}$ cell response and $B$ cell homing, modulating inflammation, activating NK cells, and connecting the innate and adaptive 
immune systems via regulating the function of dendritic cells (DC) and macrophages. Thus, IL-15 has therapeutic potential in many diseases, including cancer and infectious diseases, because this cytokine is thought to be an instructive cytokine involved in cell fate decisions that favor immunoregulatory function (1-3).

Since IL-15 was discovered, its biological applications and IL-15-based immunotherapy have been further highlighted by clinical trials focused on improving the immune response and the development of vaccines against infections and cancers (3). In fact, according to the National Cancer Institute (NIH, USA), of the 12 immunotherapeutic agents that have been used for treating cancer or for the development of cancer vaccines, IL-15 ranks first on the list because of its better ability to induce longer-lived $\mathrm{T}$ cells with higher avidity and its increased safety for tumor therapy compared to other cytokines such as IL-2 and IL-12 (4). Along with the anticipated uses for IL-15 in cancer treatment, IL-15 therapy shows promise for treating various infectious diseases. For example, IL-15 therapy boosts the anti-HIV immunity by regulating IFN- $\gamma$ secretion with the enhanced survival of $\mathrm{CD}^{+} \mathrm{T}$ cells independent of $\mathrm{CD} 4^{+} \mathrm{T}$ cells $(5,6)$. In addition, the use of IL-15 as an adjuvant in vaccine formulation enhanced the protective immunity against many intracellular pathogens, including influenza virus, Toxoplasma gondii, and herpes simplex virus, by increasing the survival and cytotoxicity of $\mathrm{T}$ and $\mathrm{NK}$ cells as well as by increasing IFN- $\gamma$ production $(5,7)$. Taken together, these previous studies suggest that IL-15 is associated with the development of IFN- $\gamma$-mediated Th1-biased response and exhibits potential for maintaining long-lasting $\mathrm{T}$ cell responses to pathogens (8).

Although the direct use or genetic modification of IL-15 has been implemented as a therapeutic against various diseases, its role in immune reconstitution by regulating immune cell differentiation is of particular interest. For example, IL-15 can facilitate immune reconstitution after bone marrow transplantation (9). In addition, human recombinant IL-15 facilitates the reconstitution of human T cells in the thymus and spleen in NOD-SCID mice (10).

IL-15 is considered an important candidate for the reconstitution of DC-mediated immune responses (11). Dendritic cells (DCs) are potent antigen-presenting cells (12) that are essential for linking the innate and adaptive immune responses. Based on the potent immune-activating properties of DCs, their use in the production of cellular vaccines is an appealing strategy for cancer immunotherapy and treatment of infectious diseases (13-15). Instead of the commonly used methods for DC differentiation, which use IL-4 for rapid expansion of DCs and introduce a possible risk of contamination during in vitro culture (16-20), an alternative method for DC differentiation involving the combination of granulocyte-macrophage colony-stimulating factor (GM-CSF) and IL-15 has also been widely used (13). Previous studies have reported that IL-15-differentiated DCs exhibit a distinct Langerhans cell-like phenotype and possess unique immunostimulatory properties $(21,22)$. Thus far, studies examining the abilities of IL-15-differentiated DCs have mostly focused on their better efficacy for T cell stimulation $(11,23,24)$. Interestingly, previous studies reported that IL-15-differentiated DCs are capable of expressing IFN- $\gamma(13,25)$; however, myeloid cell lineages expressing IFN- $\gamma$ have been disputed in many studies (26-28).

Chan et al. first discovered a third type of DCs, termed the interferon-producing killer dendritic cells (IKDCs), and thus proved that DCs could induce IFN- $\gamma$ production (29-31). As IKDCs were absent in IL-2/IL-15 receptor beta chain-deficient mice (29), IL-15 was considered a key factor for the development of IKDCs. Moreover, trans-presentation, a unique IL-15 signaling mechanism, was demonstrated to be involved in the expansion of IKDCs in vitro and in vivo (32). IKDCs were previously reported to express $\mathrm{CD} 11 \mathrm{c}^{\text {low }} \mathrm{B} 220^{+}$, even though the specific markers were different from each other (32-35). These markers are known as NK cell surface markers, which have led to controversy over the lineage of this type of cells $(34,36)$. According to their unique pathway for differentiation from bone marrow (37), ability to respond to IL-15 (32), and distinct transcriptional profile from that of NK cells (38), IKDCs seemingly belong to a subpopulation of DCs that differs from NK cells (34). More recently, these IKDCs exhibiting features of both NK cells and DCs $(29,31,36)$ now have been revisited as part of the NK cell lineage and have been renamed as premature NK cells (pre-mNK cells), resulting in an endless lineage debate $(36,39,40)$.

As another innate cell source of IFN- $\gamma$, this emerging cell family is formally now defined as innate lymphoid cells (ILCs) and has been recently identified as a part of the innate immune system, playing crucial roles in immunity, inflammation and tissue remodeling (41). This cell family has been categorized into three main groups, ILC1, ILC2 and ILC3, according to their cytokine-producing ability and transcription factor expression (42). Among the three cell groups, ILC1s were originally believed to be a homogeneous population consisting of solely NK cells. Interestingly, this putative homogeneous 
population has now been further classified into two heterogeneous subsets, NK cells and T-bet-dependent IFN-y secreting innate cells that reside within peripheral tissues (43-46). These heterogeneous ILC1s especially share the ability to produce IFN- $\gamma$ in response to IL-12, IL-15 and IL-18 cytokines, thus contributing to enhanced immunity against infectious disease $(41,47,48)$. Moreover, IL-15 is required for ILC1 development and maintenance $(47,49,50)$. Therefore, IL-15 may play an important role in contributing to the generation of ILC1 subsets. However, distinguishing the two subsets is challenging because of their phenotypical changes during inflammation $(42,51,52)$.

In view of the debates over the use of IL-15 for immune cell differentiation and the use of IL-15 in the phenotypic characterization of incompletely defined IFN- $\gamma$-producing innate cells such as IKDCs or pre-mNK cells, NK cells, NKDCs and ILC1s, in the present study, we revisited the phenotypic characteristics of the IFN- $\gamma$-producing IL-15-differentiated bone marrow-derived cells, hereafter referred to as IL-15-DBMCs (addition of IL-15 during DC differentiation with GM-CSF with/without IL-4 conventionally from bone marrow). We therefore compared the levels of cytokines and surface markers, including well-known cell markers for IKDCs or pre-mNK cells, NK cells, T cells, B cells and ILC1s in IL-15-DBMCs. In addition, we attempted to redefine specific markers on IFN- $\gamma$-producing cell population in IL-15-DBMCs by enrichment or depletion of specific markers on the IL-15-DBMCs using FACS or magnetic activated cell sorting (MACS) systems. Additionally, it has been reported that common gamma-chain cytokines, including IL-15, improve anti-bacterial and anti-viral immunity via the enhanced $\mathrm{T}$ cell response followed by potentiating the intracellular pathogen-killing function of macrophages, which supports its use in the treatment of severe infectious diseases caused by Mycobacterium tuberculosis (Mtb), human immunodeficiency virus and hepatitis B virus (53). Therefore, we assessed whether exploiting these IFN- $\gamma$-producing IL-15-DBMCs can be extended to the therapeutic potential for infectious diseases such as $\mathrm{TB}$ by examining the immune responses to Mtb-infected macrophages.

\section{Materials and Methods}

\section{Ethics statement}

All animal experiments were performed according to the guidelines of Korean Food and Drug Administration. Protocols for animal studies used in the study were approved by the Ethics Committee and Institutional Animal Care and Use Committee (2017-0049; C57BL/6J) of Yonsei University Health System (Seoul, Korea).

\section{Animals}

After approval of the study experiments, 6- to 7-week-old C57BL/6 female mice were purchased from Japan SLC, Inc. (Shizuoka, Japan) and maintained under specific pathogen-free (SPF) conditions. IFN- $\gamma \mathrm{R}^{-/-}$mice in a C57BL/6J background were purchased from the Jackson Laboratory (Bar Harbor, ME, USA).

\section{Reagents}

Murine recombinant IL-15 (R\&D, Minneapolis, MN, USA) and TLR agonists, lipopolysaccharide (LPS; E. coli 0111:B4), synthetic triacylated lipoprotein (Pam3CSK4), synthetic analog of dsRNA (Poly(I:C) HMW), and class B CpG oligonucleotide (ODN 1826) were purchased from Invivogen Inc. (San Diego, CA, USA).

\section{Generation and culture of BMDCs and IL-15-DBMCs}

BMDCs were generated from murine bone marrow cells with GM-CSF alone or GM-CSF plus IL-4 as previously described (54). Briefly, bone marrow cells were plated in petri dishes with RPMI 1640 medium supplemented with 100 units/ml penicillin/streptomycin (Lonza, Basel, Switzerland), $10 \%$ fetal bovine serum (Lonza, Basel, Switzerland), $50 \mu \mathrm{M}$ mercaptoethanol (Lonza), and $20 \mathrm{ng} / \mathrm{ml}$ of GM-CSF alone or GM-CSF plus $5 \mathrm{ng} / \mathrm{ml}$ of IL-4 and were cultured at $37^{\circ} \mathrm{C}$ in the presence of $5 \% \mathrm{CO}_{2}$. IL-15-DBMCs were prepared and cultured under the same differentiation conditions but in the BMDC medium supplemented with $10 \mathrm{ng} / \mathrm{ml}$ of IL-15. On day six, the subsequent experiments, including an analysis of cytokine levels and surface marker expression, were conducted.

\section{Cytokine measurements}

On day six of culture, cells were harvested for analysis and plated onto 12-well multi-well plates in the presence or absence of TLR agonists: $100 \mathrm{ng} / \mathrm{ml}$ of Pam3CSK4, $1 \mu \mathrm{g} / \mathrm{ml}$ of Poly(I:C), $100 \mathrm{ng} / \mathrm{ml}$ of LPS or $1 \mu \mathrm{g} / \mathrm{ml}$ of ODN. Cells were incubated for $24 \mathrm{~h}$, and then cell supernatants were collected. Supernatants were stored at $-80^{\circ} \mathrm{C}$ until use. The levels of IL-6, TNF- $\alpha$, IL-12p70, IL-10, and IFN- $\gamma$ were determined by commercially available ELISA kits according to the manufacturer's instructions (eBioscience, San Diego, CA and BD Bioscience, San Diego, CA).

\section{Flow cytometry}

To detect the expression of surface molecules on 
both cell types, cells were washed with DPBS (Welgene Inc., Daegu, Korea) and blocked with a highly specific anti-mouse CD16/CD32 (2.4G2, IgG ${ }_{2 b}$, к) antibody. The cell surface was stained with fluorescein isothiocyanate (FITC)-conjugated, anti-CD19 (eBio1D3, Rat IgG2a, א), anti-CD11b (M1/70, Rat IgG2b, к); Alexa 488-conjugated anti-CD8a (53-6.7, Rat IgG2a, א) and anti-B220 (RA3-6B2, Rat IgG2a, K); Phycoerythrin (PE)-conjugated anti-Thy1.2 (30-H12, Rat IgG2b, к), anti-CD49b (DX5, Rat IgM, k), anti-CD19 (eBio1D3, Rat IgG2a, K), and anti-MHC-II (M5/114.15.2, Rat IgG2b, k); Peridinin Chlorophyll (PerCP)-eFluor ${ }^{\circledR}$ 710-conjugated anti-PDCA-1 (eBio927, Rat IgG2b, к), anti-Siglec-H (eBio440c, Rat IgG2b); PerCP-Cy5.5-conjugated anti-CD4 (RM4-5, Rat IgG2a, к), and anti-CD11b (M1/70, Rat IgG2b, к); PE-Cy7-conjugated anti-CD11c (HL3, Hamster IgG1, $\lambda 1)$; Allophycocyanin (APC)-conjugated anti-B220 (RA3-6B2, Rat IgG2a k), anti-Thy1.2 (53-2.1, Rat IgG2a к) and anti-CD49b (DX5, Rat IgM, к); Alexa 647-conjugated anti-CD3 (17A2, Rat IgG2b, к); APC-eFluor ${ }^{\circledR}$ 780-conjugated anti-MHC-II (M5/114.15.2, Rat IgG2b, k), anti-CD127 (A7R34, Rat IgG2a, k) and anti-NK1.1 (PK136, Mouse IgG2a, k); and V605-conjugated anti-Sca-1 (D7, Rat IgG2a, к). Before use, the antibodies were diluted with DPBS containing 2\% FBS. Cells were stained for 20 to $30 \mathrm{~min}$ in the dark on the ice. Before analysis, samples were washed with DPBS containing 2\% FBS. For intracellular cytokine staining, BD Cytofix/Cytoperm kit (BD Pharmingen, San Diego, CA, USA) was used following the manufacturer's instructions. The levels of intracellular cytokines were detected with

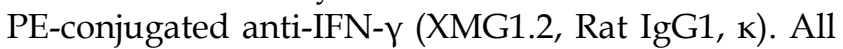
antibodies were purchased commercially (eBioscience, San Diego, CA, USA and BD Pharmingen, San Diego, CA, USA). Prepared samples were acquired on the FACSVerse or FACSCanto II flow cytometer (BD Biosciences, San Jose, CA, USA) and analyzed using FlowJo software (Tree Star, Ashland, OR, USA).

\section{Morphological analysis}

Cells cultured with GM-CSF or GM-CSF plus IL-15 were harvested and washed. Cells were cytospun in a Shandon Cytospin 3 (Thermo Scientific, Marietta, Ohio, USA) at $1000 \mathrm{rpm}$ for $5 \mathrm{~min}$ on slides with double cytofunnel sample chambers (Shandon, Thermo Scientific). Subsequently, slides were allowed to air dry and were immediately fixed with methanol (SIGMA, Aldrich, Saint Louis, MO, USA). Cells were stained in May-Grünwald-Giemsa stain diluted in 9 volumes of distilled water for $5 \mathrm{~min}$ and washed with tap water. Slides were examined by light microscopy.

\section{FACS cell sorting}

On day six of culture, both groups of cells were grown in medium with GM-CSF alone, and cells grown in medium with GM-CSF and IL-15 were harvested and stained with PE-Cy7-conjugated anti-CD11c antibody. After staining, the cells were washed with sorting buffer containing DPBS, $2 \mathrm{mM}$ EDTA (USB, Cleveland, OH, USA), 25 mM HEPES solution (4-(2-hydroxyethyl)piperazine-1-ethanesulfonic acid solution) (Sigma, St. Louis, MO, USA), and $2 \%$ bovine serum albumin (Sigma). Cell sorting was performed with a FACSAria (BD Biosciences, San Jose, CA, USA). The purity of the cell separation was over $94 \%$.

\section{MACS}

To enrich or deplete cells expressing the targeted markers, antibody-conjugated magnetic beads were used for cell sorting. On day six of culture, both groups of cells were harvested, and CD 90.2, B220, and CD19 MicroBeads (Miltenyi Biotce, Bergisch Gladbach, Germany) were used according to the manufacturer's instructions with the QuadroMACS separation unit attached to a MACS multi-stand and LS or LD columns.

\section{Bacterial strains and cultures}

M. tuberculosis strain $\mathrm{H} 37 \mathrm{Rv}$, stored at the International Tuberculosis Research Center (ITRC, Masan, Korea), was used in this study. M. tuberculosis was cultured aerobically at $37^{\circ} \mathrm{C}$ in Middlebrook $7 \mathrm{H} 9$ medium (Difco Laboratories, Detroit, MI, USA) containing $0.02 \%$ glycerol (Sigma, Saint Louis, MO, USA) supplemented with $10 \%$ oleic acid-albumin-dextrose-catalase (OADC) (Becton Dickinson, Sparks, MD, USA) for 4 weeks. Enumerated bacteria were used for the subsequent macrophage infection experiment as described below.

\section{Nitric oxide detection}

Nitric oxide (NO) was detected with enzymatic reduction of $\mathrm{NO}_{3}$ by nitrate reductase, followed by spectrophotometric analysis of total nitrite using Griess reagent. This method was conducted according to the manufacturer's instructions (iNtRON Biotechnology, Gyeonggi, Korea).

\section{Growth of $M$. tuberculosis in bone marrow-derived macrophages (BMDMs) co-cultured with sorted IFN-Y-producing IL-15-DBMCs}

To compare the effect of pathogenesis of the $M$. tuberculosis strain $\mathrm{H} 37 \mathrm{Rv}$ on infected macrophages with added cells, BMDMs were infected at one bacterium per cell in antibiotic-free DMEM (Biowest, 
Nuarille, France) and incubated for $4 \mathrm{~h}$. The wells were then thoroughly washed with prewarmed DPBS to remove extracellular bacteria and then incubated again in antibiotic-free media for the adaptation of the bacteria in cells. After $24 \mathrm{~h}$ of incubation, each well was washed with DPBS, and Mtb-infected BMDMs were co-cultured with the sorted cells from IL-15-DBMCs; cells were added to the MOI of 1:1 or/and 1:5. Three days after infection, cells were lysed with $0.05 \%$ Triton X-100 (Sigma) prepared in sterile water. The lysates were serially diluted in sterile DPBS and spotted onto Middlebrook 7H10 agar (Difco) supplemented with 10\% OADC. The bacterial colony-forming units (CFU) were enumerated after the bacteria were incubated for 4 weeks at $37^{\circ} \mathrm{C}$.

\section{Statistical analysis}

All the experiments were repeated at least three times with consistent results. Representative data in the graphs are presented as the mean \pm standard deviation (SD). The data comparisons from the experiment among samples were determined by an unpaired $t$-test or one-way ANOVA followed by Tukey's multiple comparison test distribution using statistical software (GraphPad Prism Software, version 5.0, San Diego, CA, USA). Statistical significance was considered at ${ }^{*} p<0.05,{ }^{* *} p<0.01$, and ${ }^{* *} p<0.001$.

\section{Results}

\section{Addition of IL-15 to DC differentiation conditions generates IFN-Y-producing cells with differential expression levels of DC surface markers}

The generation of IFN- $\gamma$-producing innate cells, such as IKDCs or pre-mNK cells, NKDCs, and ILC1s, is known to be IL-15-dependent $(29,36,47)$. To confirm how IL-15 affects cell differentiation and the generation of IFN- $\gamma$-producing cells, we used an ELISA to measure the levels of various cytokines, such as IL-12p70, TNF- $\alpha$ and IFN- $\gamma$, followed by LPS stimulation. The total number of generated cells was not different between BMDCs $\left(1.8 \times 10^{8}\right.$ cells/mouse $)$ and IL-15-DBMCs $\left(1.7 \times 10^{8}\right.$ cells/mouse) after 6 days of culture. While there was no significant difference in the production of TNF-a between the BMDCs and IL-15-DBMCs, the level of IFN- $\gamma$ was dramatically up-regulated in the IL-15-DBMCs only after the LPS treatment (Fig. 1A). Moreover, compared to BMDCs, IL-15-DBMCs began producing IFN- $\gamma$ at 3 hours post-stimulation (Fig. S1A). Regarding IL-12p70, although IL-15-DBMCs appeared to produce more IL-12p70 than BMDCs, both cells produced IL-12p70 to some extent; moreover, BMDCs had no ability to produce IFN-ү. Additionally, while both BMDCs and IL-15-DBMCs displayed similar TNF- $\alpha$-producing capacities against differential TLR agonist stimulation, except for under Poly(I:C) stimulation, IFN- $\gamma$ production was observed in IL-15-DBMCs only, not in BMDCs (Fig. S1B). Thus, we hypothesized that an IL-15-specific cell population, which was generated by IL-15 addition during DC differentiation, produces IFN- $\gamma$ and that the entire IL-15-DBMC population can produce IFN- $\gamma$ in response to various TLR agonists. IL-4, which has been used for in vitro DCs by some groups, is known to inhibit DC-produced IL-12p70 and to be involved in the development of Th2 cells (24). Therefore, we confirmed whether IL-4 affects the cytokine profile patterns. While the levels of IFN- $\gamma$, IL-12p70, IL-10 and TNF- $\alpha$ were higher in cells cultured in GM-CSF-only medium than in cells cultured in GM-CSF plus IL-4 medium, the cytokine profile patterns of BMDCs and IL-15-DBMCs were not affected by IL-4 (Fig. S2A). Moreover, the concentration of GM-CSF rarely impacted cytokine production levels (Fig. S2B). Regarding morphological features, no differences in size or granularity were observed between the two cell types based on forward scatter and side scatter plots (Fig. 1B). Moreover, a population of non-adherent floating cells was observed among the IL-15-DBMCs that was morphologically similar to BMDCs on day six of culture (Fig. S2C), and this population was obvious despite more abundant dark granules in the IL-15-DBMCs. Interestingly, IL-15 addition reduced the percentage of $\mathrm{CD} 11 \mathrm{c}^{+} \mathrm{MHC}-\mathrm{II}^{+}$cells, which are mature DC markers (Fig. 1C). Moreover, while the CD11chi population in IL-15-DBMCs was lower than that of BMDCs, the CD11 $c^{\text {int }}$ population significantly increased, and the MHC-IIlo population expanded (Fig. 1D). These results suggest that IL-15 addition during DC differentiation generates a phenotypically distinguishable IL-15-DBMC population with IFN- $\gamma$-producing capacity.

\section{Primary phenotypic characterization of IFN-Y-producing CD $11 \mathrm{c}^{\text {int }}$ populations in IL-15-DBMCs}

IFN-Y production and the CD11 $c^{\text {int }}$ population appear to be distinct events in IL-15-DBMCs. Thus, we presumed that there would be a correlation between the expression of CD11c and the production of IFN- $\gamma$. We performed cell sorting with a FACSAria to separate the three cell populations depending on the mean fluorescence of CD11c (Fig. 2A). Interestingly, after LPS stimulation for $24 \mathrm{~h}$, the levels of TNF-a in the BMDCs and IL-15-DBMCs were similar in all three populations. In contrast, a 
significant increase in the level of IFN- $\gamma$ production was observed in the CD11 $c^{\text {int }}$ population only in IL-15-DBMCs, and both CD11chi and CD11cIL-15-DBMCs produced negligible amounts of IFN- $\gamma$ (Fig. 2B). IKDCs (IFN- $\gamma$ producing killer dendritic cells) and plasmacytoid dendritic cells (pDCs) are known for their intermediate CD11c expression (55). Therefore, we evaluated the levels of various markers specific for IKDCs or pDCs for further characterization. Moreover, we analyzed markers that were specifically expressed in the CD11cint cell population in IL-15-DBMCs but not in BMDCs (Fig. $2 \mathrm{C})$. BMDCs and the CD11 $\mathrm{c}^{\text {int }}$ cell population in IL-15-DBMCs did not exhibit differences in the mean fluorescence of CD4, CD8, PDCA-1, NK1.1, CD49b or Siglec-H. However, the CD11 $c^{\text {int }}$ cell population in IL-15-DBMCs expressed considerably lower levels of CD11b and MHC-II and higher levels of B220 than those expressed in BMDCs. Consequently, the level of B220 expression in the CD11 $\mathrm{c}^{\text {int }}$ cell population in IL-15-DBMCs was also significantly higher than that in either the BMDC-derived CD11 $c^{\text {int }}$ population or the IL-15-derived CD11 ${ }^{\text {hi }}$ population (Fig. S3). For the subsequent experiments, we excluded conditions where there were no alterations or conditions where ambiguous markers were expressed on the CD11 $c^{\text {int }}$ cell population in IL-15-DBMCs compared with those on BMDCs.

A

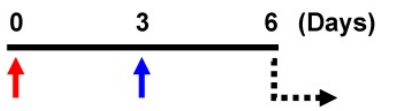

个 IL-15 treatment or not

个 Media addition

i Stimulation \& Analysis

B

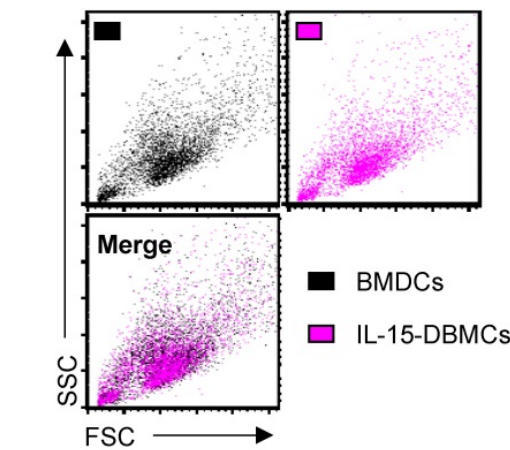

D

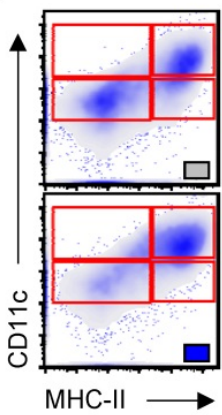

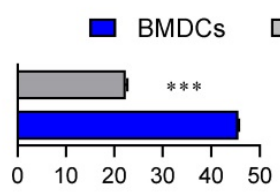

CD11chiMHC-IIhi (\%)

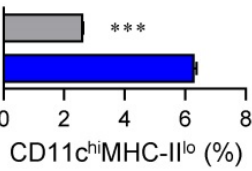

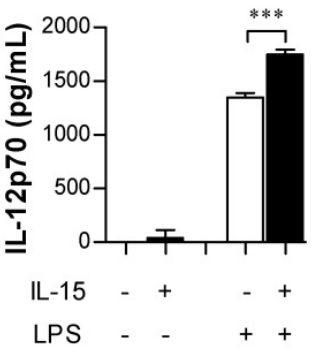
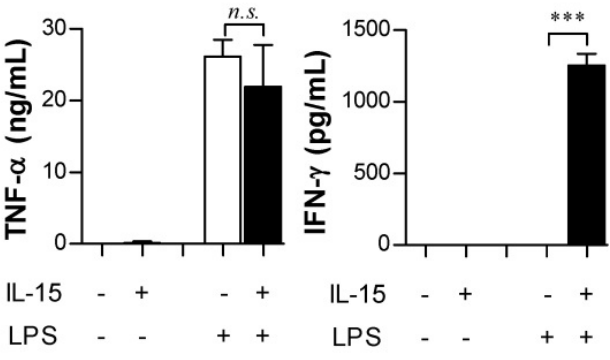

C
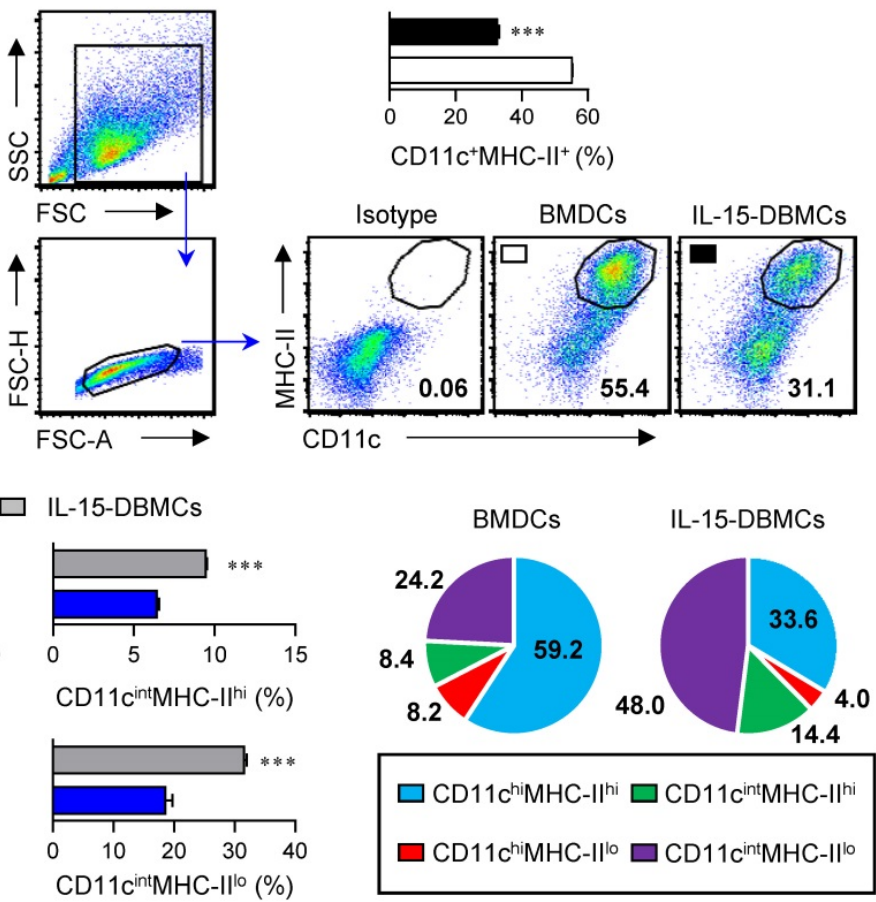

Figure 1. IL-15-differentiated bone marrow-derived cells (IL-15-DBMCs) produced significant levels of IFN-Y along with decreased levels of common dendritic cell markers. (A-D) BMDCs or IL-15-DBMCs were differentiated from bone marrow in the presence of GM-CSF alone or GM-CSF plus IL-15, respectively. (A) Scheme of the experimental design for cell generation. Bone marrow cells treated with or without (red arrow) IL-15 on day 0 of cell generation were subsequently treated with media at 3 days post cell culture (blue arrow). After 6 days of culture, each differentiated cell population (106/ml) was stimulated with $100 \mathrm{ng} / \mathrm{ml}$ of LPS for $24 \mathrm{~h}$ (dashed arrow). Cytokines were measured by ELISA with culture media (mean $\pm S D ; n=3$ ). (B) Each cell population group was analyzed by forward scatter and side scatter via flow cytometric analysis. One representative plot from three independent experiments is described. (C) Expression of CDIIc and MHC-Il in each group of cells. The number of squares indicates the percentage of the corresponding population. The proportion of CD $11 \mathrm{c}^{+} \mathrm{MHC}-\mathrm{II}^{+}$cells is represented by bar charts (mean \pm SD; $n=3$ ). (D) Expression of CD $11 \mathrm{c}$ and MHC-II

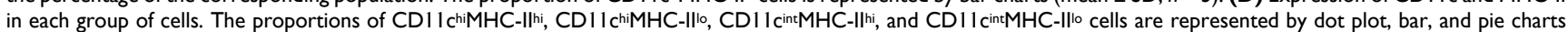
(mean $\pm \mathrm{SD} ; n=3$ ). The significance of differences was determined using an unpaired $t$-test. n.s.; not significant, $* * * p<0.001$ comparison between BMDCs and IL-15-DBMCs. 
A

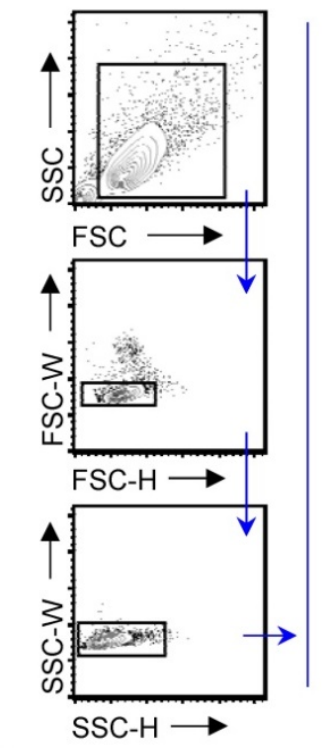

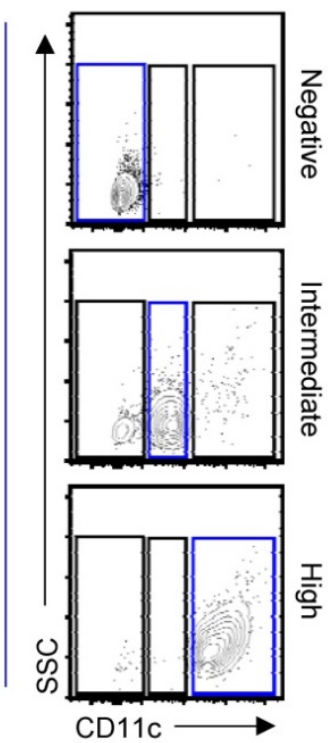

B
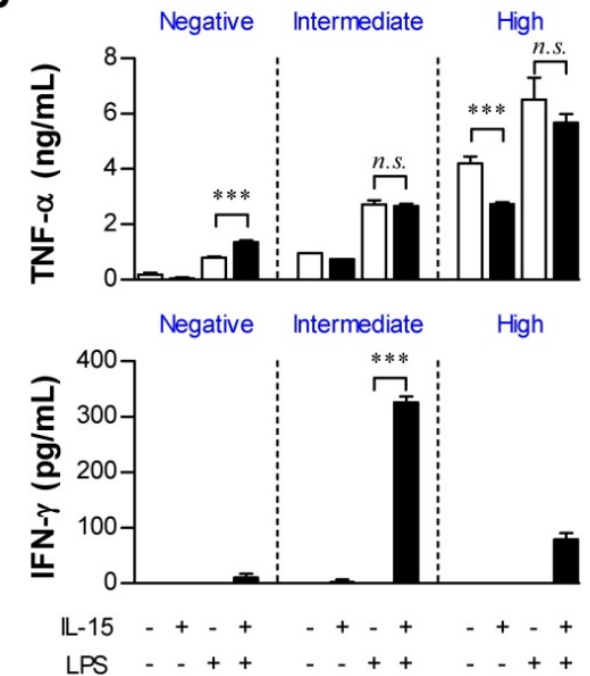

C
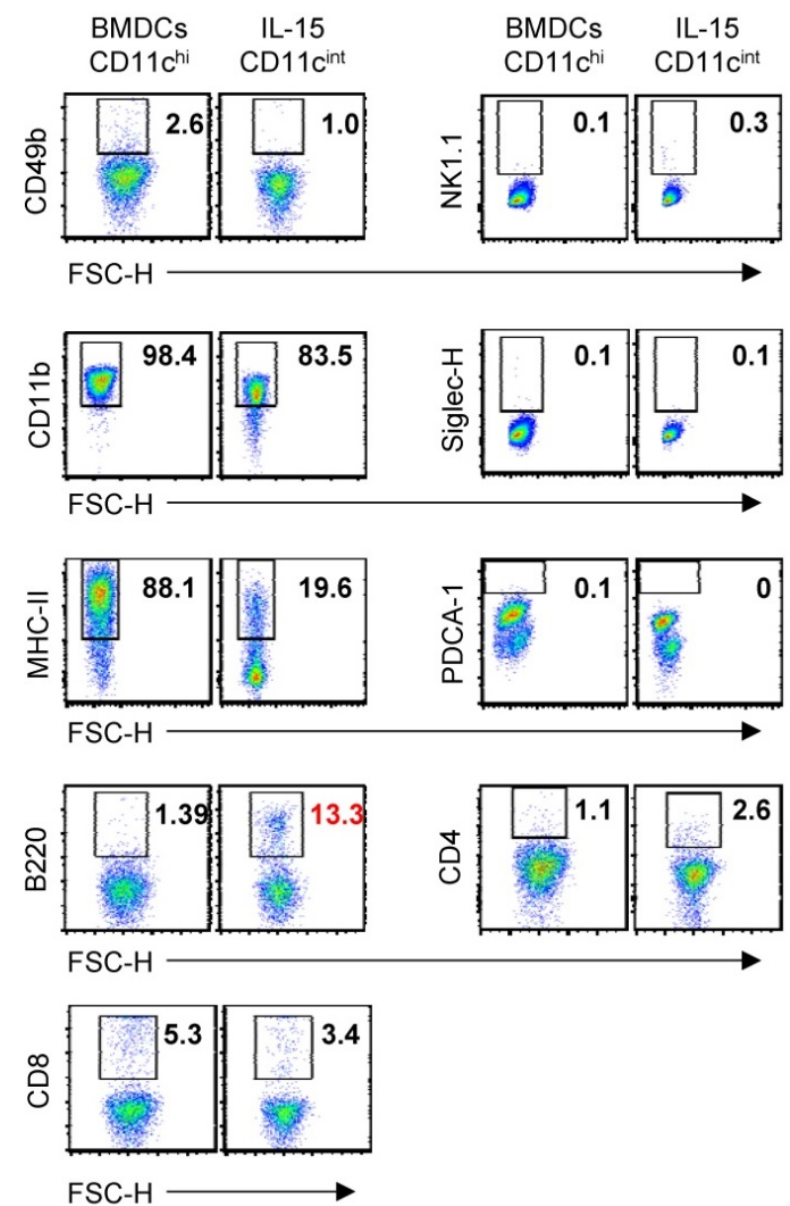

Figure 2. CDIIcint population in IL-15-DBMCs is a major source of IFN-Y production and differentially expresses surface markers in comparison with BMDCs. (A) CDI l c $c^{+}, C D 11$ cint, and CDI lc- population in BMDCs and IL-15-DBMCs were isolated by FACS. One representative plot from three independent experiments is described. (B) Each sorted cell population $(105 / \mathrm{ml})$ was stimulated with $100 \mathrm{ng} / \mathrm{ml}$ of LPS for $24 \mathrm{~h}$. Cytokines were measured by ELISA with culture media (mean \pm SD; $n=$ 3). (C) On day of six, BMDC-derived CDI l chi and IL-15-DBMC-derived CDI 1 cint cells were stained for the indicated markers and compared between the two cell populations. The number of squares indicates the percentage of the corresponding population. One representative plot from three independent experiments is described. The significance of the difference was determined using an unpaired $t$-test. n.s.; not significant, ${ }^{*} p<0.05$, ${ }^{*} p<<0.01, *^{*} p<0.001$ comparison between BMDC and IL-15-DBMCs.

\section{Advanced phenotypic characterization of

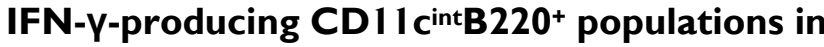 IL-15-DBMCs}

As shown in Figs. 1 and 2, due to increased percentages of CD11cint and B220 $0^{+}$in IL-15-DBMCs, we presumed that these two markers are associated with the IFN- $\gamma$-producing capacity of IL-15-DBMCs. Although we showed no expression alterations of NK cell-specific CD49b and NK1.1 or T cell-specific CD4 and CD8 molecules in IFN- $\gamma$-producing CD11 $c^{\text {int }}$ IL-15-DBMCs and BMDCs (Fig. 2C and Fig. S3), we further investigated lymphoid cell lineage-specific markers to exclude the possible expansion of these cells due to their IFN- $\gamma$-producing abilities. In addition, cells with the $\mathrm{CD} 11 \mathrm{c}^{\mathrm{int}} \mathrm{B} 220^{+}$phenotype were heterogeneous, as these markers were expressed not only by diverse DC subsets but also by $\mathrm{B}, \mathrm{T}$, and NK cells (56). Therefore, we evaluated differences in the expression of B-, T-, or NK cell-associated surface markers between BMDCs and IL-15-DBMCs, and we found no relationships with these markers except for Thy1.2 and B220 (Fig. S4). The number of IL-15-induced CD11 $\mathrm{c}^{\text {int }} \mathrm{B} 220^{+}$cells was approximately $6 \times 10^{6}$ cells/mouse, but only $3 \times 10^{5}$ cells/mouse were generated in BMDCs after 6 days of culture, suggesting that IL-15 induced the expansion of this IFN- $\gamma$-producing cell population. Only the LPS-stimulated CD11 $\mathrm{c}^{\text {int }} \mathrm{B} 220^{+}$subpopulation, not the rest of the generated population, in IL-15-DBMCs 
displayed increased IFN- $\gamma$ levels compared with those of the control cells and BMDCs by intracellular molecule staining analysis, which was consistent with the ELISA results (Fig. 3A, B). These results indicate that IFN- $\gamma$ production followed by LPS stimulation in IL-15-DBMCs are related in CD11 $\mathrm{c}^{\text {intB220 }}{ }^{+}$cells. Moreover, we further observed additional cell surface markers that have been associated with IFN- $\gamma$-secreting cell populations such as ILCs (Fig. $3 \mathrm{C})$. Because the rate of $\mathrm{B}_{220^{+}}$cells from both groups of cells was very low, we enriched the B220+ population by MACS and analyzed the level of phenotype markers. Although expression of CD127 was not significantly different among the different populations, the percentages of cells expressing Sca-1 and Thy1.2 were markedly increased in the B220-enriched CD11 $\mathrm{c}^{\text {int }}$ population derived from IL-15-DBMCs (Fig. 3C).

\section{Thy 1.2 is a specific marker for IFN-y-producing CD 11 cintB220+ IL-15-DBMCs}

Thy1.2 and Sca-1 have been reported as surface markers of ILCs, including ILC1s associated with IFN- $\gamma$ production (57-59). To confirm whether Thy1.2 is a characteristic marker of IFN- $\gamma$-producing IL-15-DBMCs based on the present results (Fig. 3C), we examined the effect of Thy1.2. First, we sorted Thy $1.2^{+}$cells from both BMDCs and IL-15-DBMCs by flow cytometry using an anti-mouse Thy1.2 antibody. There was no difference among the populations of Thy1.2 ${ }^{+}$cells in each group (Fig. 4A). Next, Thy1.2+ cells of each group were enriched using B220+ MicroBeads and MACS separators. The LPS-stimulated Thy1.2+ and B220-enriched cells (Fig. 4B, left panel) from IL-15-DBMCs exhibited a higher level of the CD11 $\mathrm{c}^{\text {int }}$ population than the other cell groups. This cell population comprised $85 \%$ of the Thy $1.2^{+} \mathrm{CD} 11 \mathrm{c}^{\text {int }} \mathrm{B} 220^{+}$population, which expressed
A

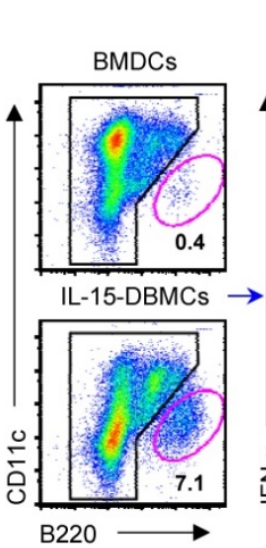

C

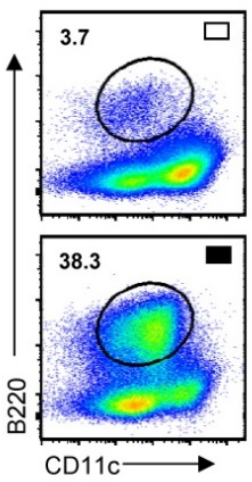

B

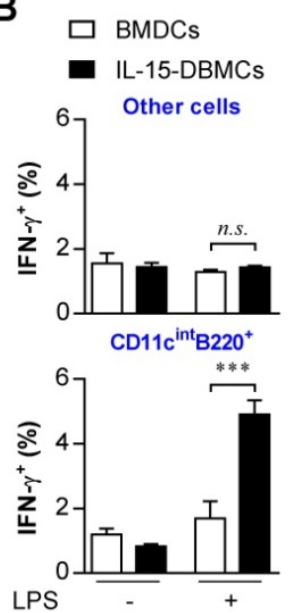

LPS
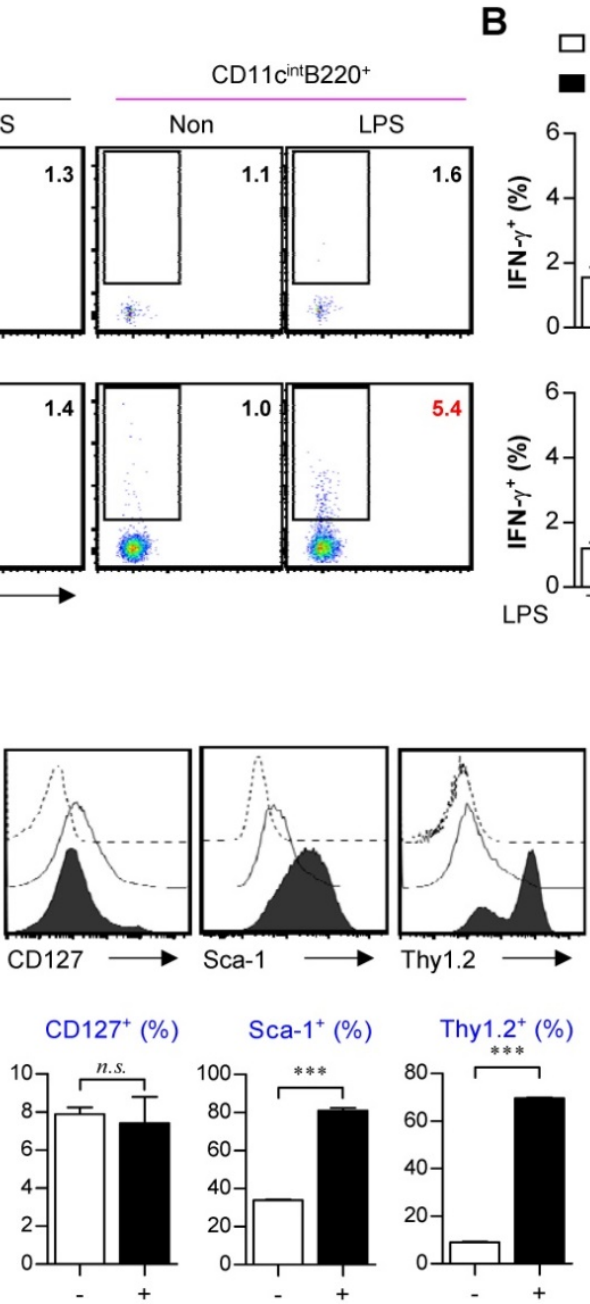

¿- Isotype

$\square$ BMDCs

- IL-15-

IL-15-DBMCs
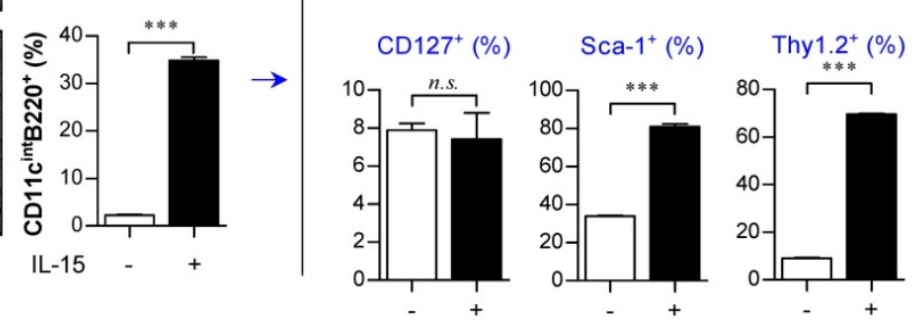

Figure 3. CDIIcintB220+ population in IL-15-DBMCs is a major producer of IFN-Y and immunophenotypically differs from BMDCs by differentially expressing Sca-1 and Thy1.2. (A) BMDCs and IL-15-DBMCs stimulated with LPS for $6 \mathrm{~h}$ with GolgiStop were analyzed for the expression of IFN-Y by an intracellular staining (ICS) assay. The numbers in the plots represent the percentage of the corresponding population. (B) The bar graph represents the mean \pm SD $(n=3)$ of the IFN- $\gamma^{+}$ population in gated areas of CD1 1 cintB220+ and other cells. (C) BMDCs and IL-15-DBMCs were enriched for the B220+ population by MACS, and CD1 1 cintB220+ cells from each population were stained for the indicated markers. The results are presented as the mean \pm SD $(n=3)$. The significance of the difference was determined using an unpaired $t$-test. n.s.; not significant, $* * * p<0.001$ comparison between CD1 1 cintB220+ cells from BMDCs and IL-15-DBMCs. 
significantly higher levels of IFN- $\gamma$ than other groups (Fig. 4B). As displayed in Fig. 4B, these results suggest that the $\mathrm{CD} 11 \mathrm{c}^{\text {int }} \mathrm{B} 220^{+}$-expressing Thy1.2 population in IL-15-DBMCs is associated with IFN- $\gamma$ production.

\section{Confirmation of phenotypic markers on IFN-Y-producing IL-15-DBMCs}

Next, we attempted to confirm whether the discovered markers may be distinct markers for IFN- $\gamma$-producing IL-15-DBMCs by inverse FACS gating of intracellularly IFN- $\gamma$-expressing IL-15-DBMCs. Before that, we confirmed that these IFN- $\gamma$ producing capacities of IL-15-DBMCs were consistent with the ELISA results (Fig. S5). Upon depletion using B220 and Thy1.2 Microbeads, the capacity of LPS-treated B220 or Thy1.2-depleted IL-15-DBMCs to produce IFN- $\gamma$ was significantly reduced. On the other hand, when CD19 was deficient in IL-15-DBMCs, marginally decreased IFN- $\gamma$ production was observed. This reduction might be partly due to the loss of $\mathrm{CD} 19^{+}$cells co-expressing B220, and it indicated that $B$ cells were not related to IFN- $\gamma$-producing cells (Fig. S5A, B and C). Notably, the intracellular appearance of IFN- $\gamma$ was shown in the $\mathrm{B} 220^{+}$, Thy $1.2^{+}, \mathrm{CD} 11 \mathrm{c}^{\mathrm{int}}$, and $\mathrm{Sca}-1^{+}$populations from LPS-treated B220-enriched IL-15-DBMCs (Fig. S6). Thus, we investigated whether the increased levels of LPS-stimulated IFN- $\gamma$ in IL-15-DBMCs was induced by Sca- $1^{+}$cells in the Thy $1.2^{+} \mathrm{CD} 11 \mathrm{c}^{\text {int }} \mathrm{B} 220^{+}$ subpopulation. First, we measured the intracellular levels of IFN- $\gamma$ by flow cytometry using the Golgi blocker brefeldin A (BFA). The accumulation of intracellular IFN- $\gamma$ in B220-enriched IL-15-DBMCs was nine-times more robust than that of the other groups (Fig. 5A). Next, we investigated whether the targeted cell surface markers could play a role in

A
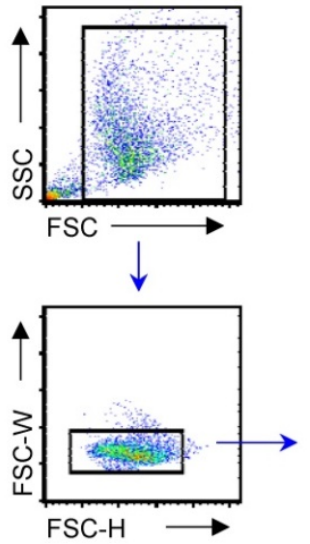

B
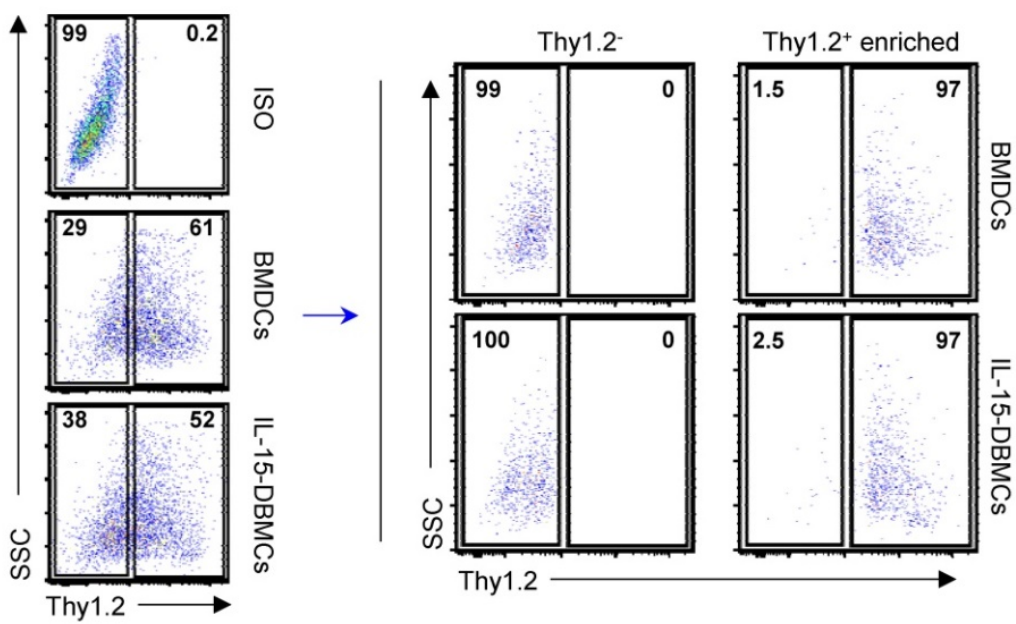

Thy $1.2^{+} \mathrm{B} 220^{+}$

Thy $1.2^{+} \mathrm{B} 220^{-}$
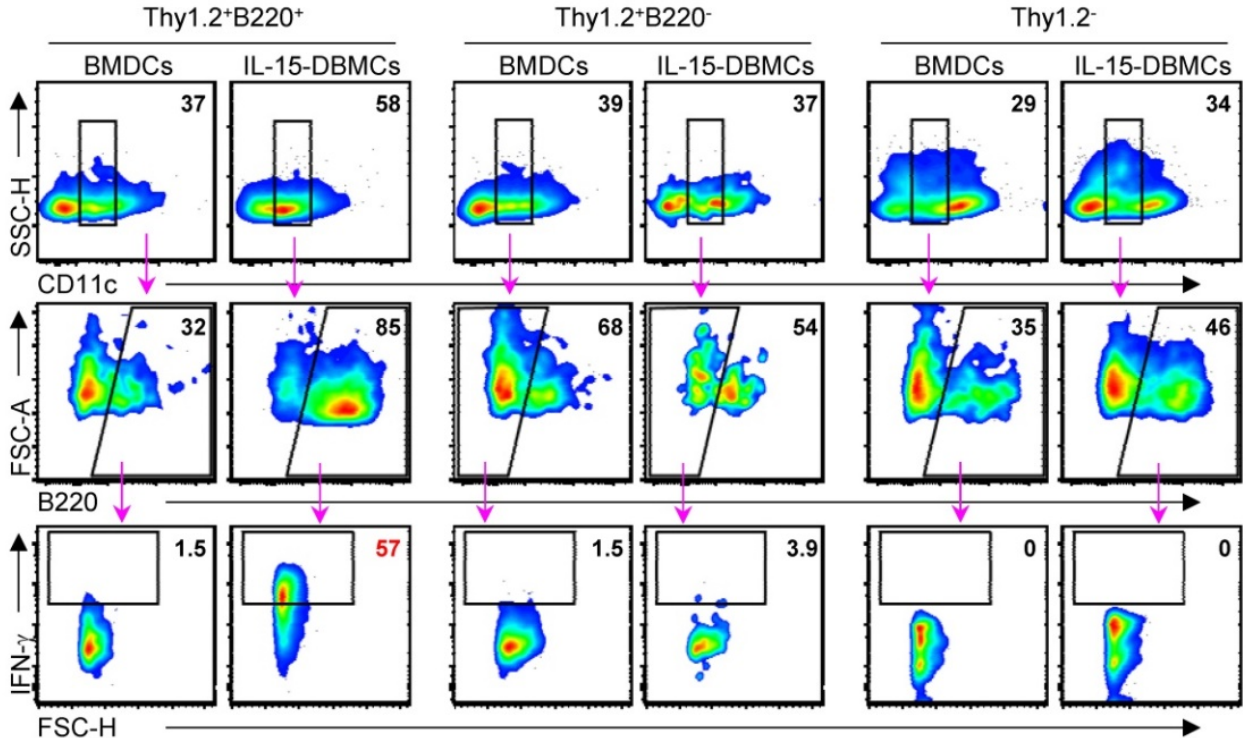

Figure 4. Thy 1.2 is a key phenotypic marker for IFN-y-producing B220+ IL-15-DBMCs. One representative plot from three independent experiments is described. (A) Thy 1.2+ cells were isolated from BMDCs and IL-15-DBMCs. The numbers in the plots represent the percentage of the corresponding population. (B) Thy1.2- cells and the B220-enriched/depleted population from Thy1.2+ cells were analyzed for the expression of IFN-y by ICS assay. The numbers in the plots represent the percentage of the corresponding population. 
IFN- $\gamma$ production. Importantly, the significant increase in the level of IFN- $\gamma$ production in the $\mathrm{B} 220^{+}$, Thy $1.2^{+}, \mathrm{CD} 11 \mathrm{c}^{\text {int }}$, and Sca- $1^{+}$populations occurred only after B220-enriched IL-15-DBMCs were treated with LPS (Fig. 5B). Collectively, these data suggest that the source of IFN- $\gamma$ is the

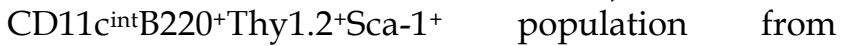
IL-15-DBMCs. As displayed in Fig. 5C, IL-15-DBMCs were analyzed and then confirmed by backgating from IFN- $\gamma^{+}$cells using a flow cytometry strategy. Approximately $3.3 \times 10^{6}$ cells/mouse of IFN- $\gamma$-associated CD11 $c^{\text {intB220 }} 0^{+}$Thy $1.2^{+}$Sca- $1^{+}$cells were generated. These results indicate that IL-15 treatment generates cells that are functionally and phenotypically similar to both Sca-1+Thy $1.2^{+}$ ILC1-like cells and B220 ${ }^{+} \mathrm{CD} 11 \mathrm{c}^{\text {int }}$ IKDCs-like cells as the major subset of IFN- $\gamma$ producing cells, apart from NK cells, indicating that IFN- $\gamma$-producing IL-15-DBMCs resemble both cell types by reciprocally expressing specific markers of both cell types.

A

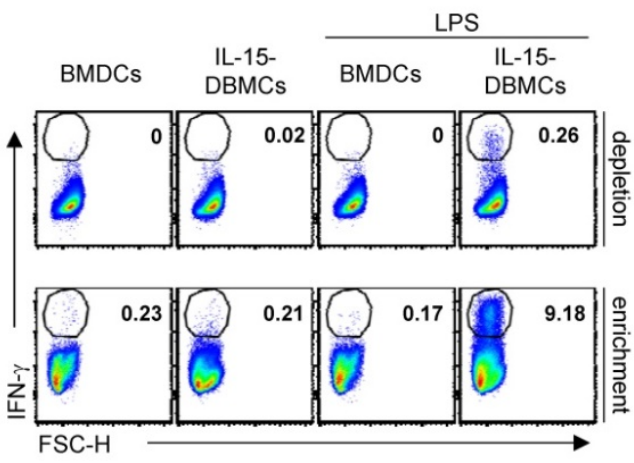

C

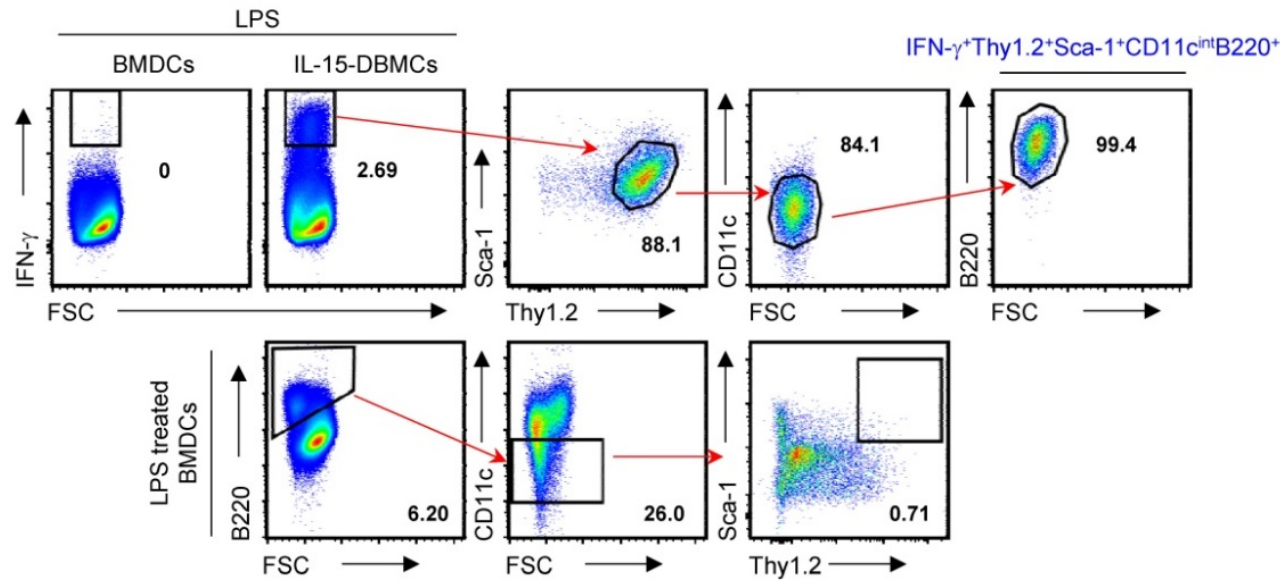

B

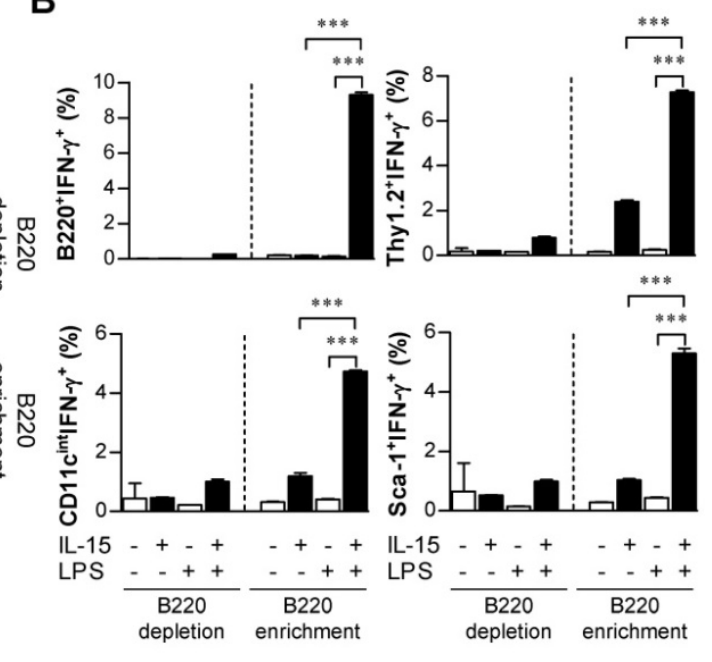

\section{IL-1 5 expands IFN- $\gamma$-producing IL-15-DBMCs in freshly isolated mouse bone marrow}

To further check whether IL-15 directs the expansion of pre-existing IL-15-DBMCs or induces the differentiation of IL-15-DBMCs, bone marrow was freshly isolated from mice. Interestingly, $1.5 \times 10^{4}$ cells

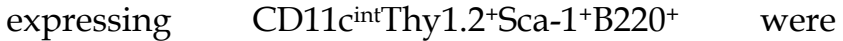
observed, which constituted $0.03 \%$ of the total bone marrow cells (Fig. 6A). Moreover, this IL-15-DBMC population was not associated with the NK1.1 surface marker (Fig. 6B), suggesting that the NK cell-derived IFN- $\gamma$-producing capacity upon LPS stimulation may be excluded as we consistently described. Based on this pre-existence, we examined the expansion of IL-15-DBMCs in a time-dependent manner. When treated with IL-15 under the DC-generating condition, the CD11cint-expressing population consistently started to expand, and the proportion of Thy $1.2^{+}$Sca- $1^{+} \mathrm{B} 220^{+}$cells among the CD11 ${ }^{\text {int }}$ cells was 
significantly increased from the beginning of culture. This increased cell population was not observed under the GM-CSF-only condition (Fig. 6C and D). These results demonstrated that IL-15 induced the

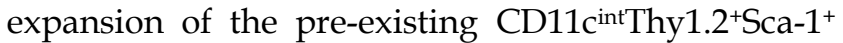
$\mathrm{B} 220^{+}$cell population rather than generating a new cell population.

\section{IFN-y-producing Thy1.2+B220+ IL-15-DBMCs contribute to the control intracellular Mtb infection}

IFN- $\gamma$ is widely believed to have an essential role in controlling tuberculosis (60-63). This cytokine is mainly produced by Th1 cells, which have a key role in Mtb resistance. IFN- $\gamma$ activates infected macrophages, which kill bacteria through the production of nitric oxide, reactive nitrogen intermediates, and reactive oxygen species (64). In addition, $\mathrm{CD}^{+} \mathrm{T}$ cells, innate lymphocytes, NK cells and NKT cells can produce IFN- $\gamma$. However, while
Mtb migrates from the lung to other organs during the initial resident phase within seven to nine days, permissive macrophages accumulate in the lung, resulting in the delayed arrival of Mtb-specific T cells at the primary infection site, which occurs within 18-20 days (65).

According to these findings, a robust early innate immune response to Mtb infection was expected to help limit bacterial growth. In this study, Mtb H37Rv-infected BMDMs were co-cultured with IL-15-DBMCs, which were enriched for the presence or absence of Thy1.2 and B220 using flow cytometric analysis (Fig. 7A). Given that Mtb has been reported to activate TLR2 (66) and that IL-15-DBMCs can produce IFN- $\gamma$ upon TLR2 activation using Pam3CSK4 (Fig. S1), the Thy1.2- and B220-enriched cell population produced significant levels of IFN- $\gamma$ in response to Mtb infection (Fig. 7A).
A
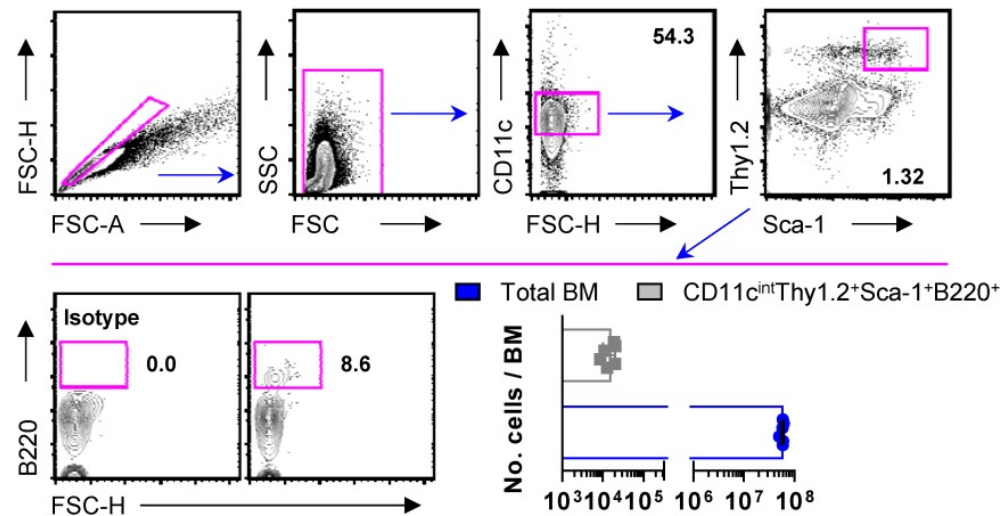

C
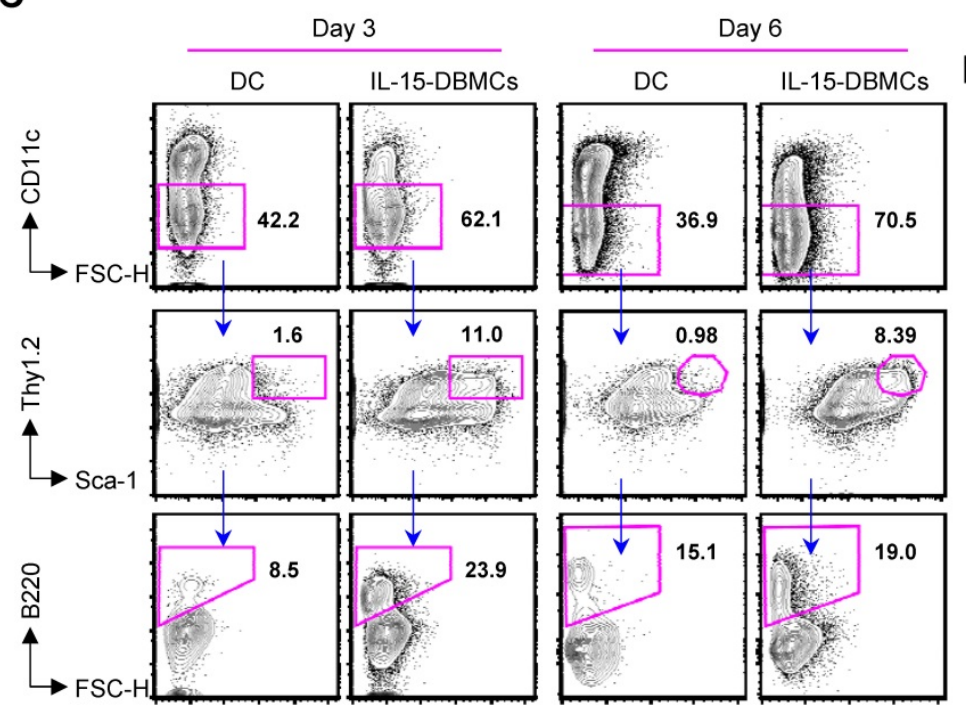

B

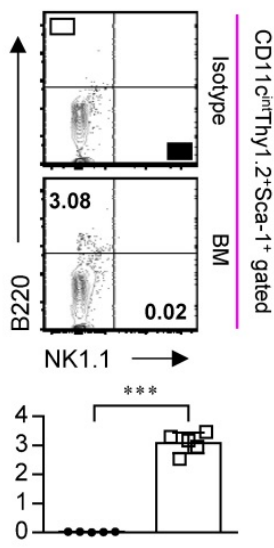

Level of expression (\%)

- BM (Day 0)

$\square$ DC

$\square$ IL-15-DBMCs

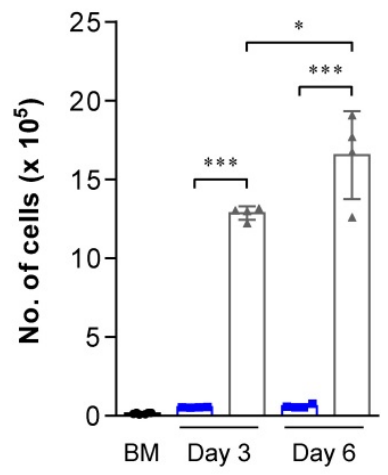

Figure 6. IL-15 directly contributes to the expansion of the CD1 I cintThy1.2+Sca-1+B220+ cell population from bone marrow. (A) Freshly isolated mouse bone marrow samples were surface stained with the indicated surface markers. The numbers in the plots represent the percentage of the corresponding population. (B) IL-15-DBMC-derived target cell populations were further stained with the NK1.1 surface marker. The numbers in the plots represent the percentage of the corresponding population. The results are presented as the mean \pm SD $(n=5)$. (C) The expression of CD11c, Thy1.2, Sca-1 and B220 was compared between DCs and IL-15-DBMCs. The number of squares indicates the percentage of the corresponding population. (D) The absolute number of the corresponding population in each group of cells is represented by the bar graph (mean $\pm \mathrm{SD} ; n=4)$. 
A

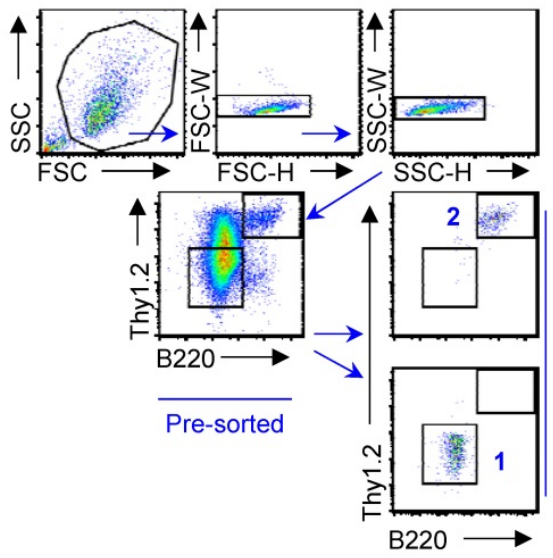

B

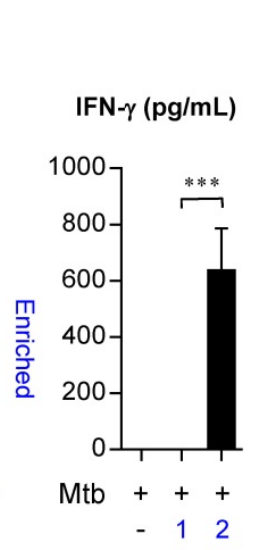

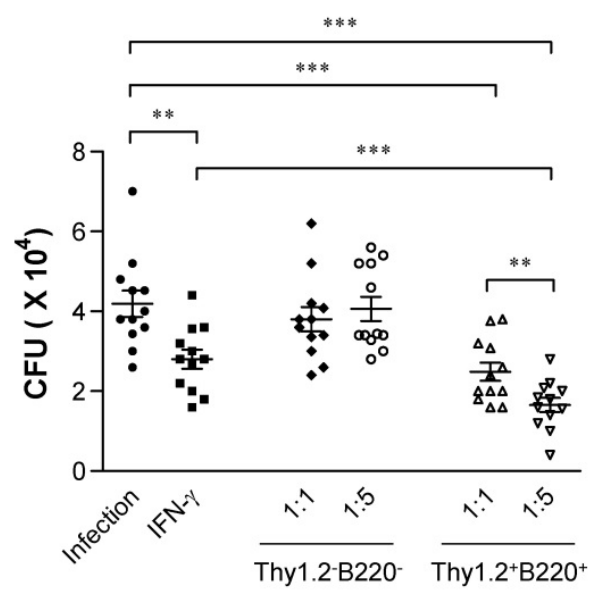

C

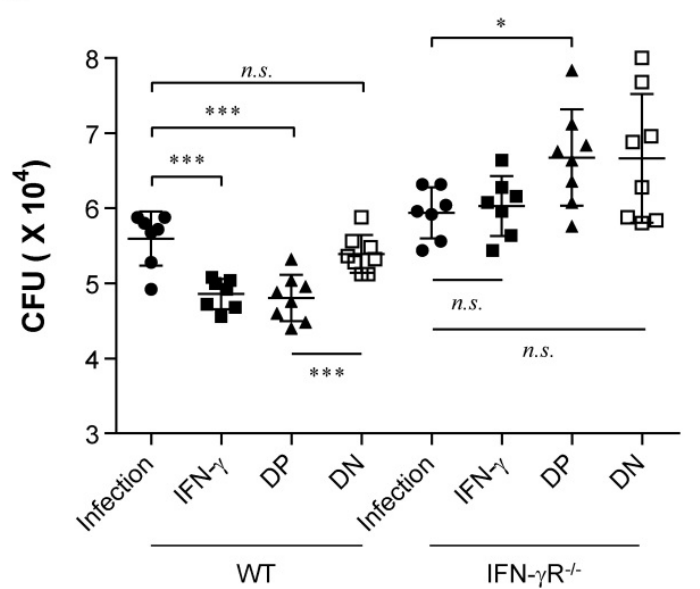

D

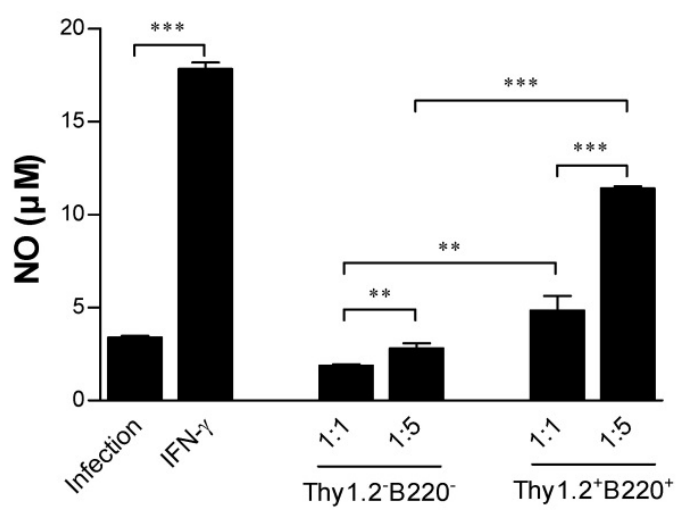

Figure 7. IFN-y-producing sorted B220+Thy 1.2+ cells from IL-15-DBMCs restrict intracellular growth of Mycobacterium tuberculosis in BMDMs. (A) Thy1.2and B220-enriched or Thy1.2- and B220-depleted cell populations derived from IL-15-DBMCs were harvested through FACSAria sorting. Then, IL-15-DBMC-derived populations enriched or depleted in B220 and Thy1.2 were stimulated with Mtb, and the levels of IFN-y in the cell supernatant were analyzed. (B) IL-15-DBMC-derived B220and Thy1.2-enriched/depleted cells were added to Mtb-infected macrophages, and the intracellular proliferation of bacteria was monitored after three days of co-culture. CFU are representative of two independent experiments. (C) Conditioned media derived from B220- and Thyl.2-enriched/depleted cells were added to Mtb-infected wild-type and IFN- $\gamma \mathrm{R}^{--}$macrophages, respectively. Then, the intracellular proliferation of bacteria was monitored after three days of co-culture. CFU are representative of two independent experiments. DP, double positive; DN, double negative. (D) The levels of NO were detected by Griess reagent. The results are presented as the mean \pm SD ( $n=3$ ). One-way ANOVA followed by Tukey's multiple comparison test was used to evaluate statistical significance. n.s.; not significant, ${ }^{*} p<0.05$, $* * p<0.01, * * * p<0.001$.

Based on IFN- $\gamma$-producing capacity, cells were lysed and spotted onto 7H10 plates on day three of co-culture. After 3 weeks of incubation, the CFU were counted. As a positive control, $50 \mathrm{ng} / \mathrm{ml}$ of IFN- $\gamma$, known for its killing effect on Mtb $(67,68)$, was added to infected macrophages, and bacterial growth was observed (Fig. 7B). To further confirm the IFN- $\gamma$-derived protective effect, IFN- $\gamma \mathrm{R}^{-/-}$BMDMs were infected with $\mathrm{Mtb}$ and co-cultured with double-positive- and double-negative-conditioned media with or without Pam3CSK4 stimulation, respectively (Fig. 7C). Compared to the groups of macrophages mixed with Thy1.2- and B220-depleted cells or culture media only, the group incubated with IL-15-DBMC-derived Thy1.2- and B220-enriched cells showed suppressed bacterial growth (Fig. 7B). In addition, conditioned media from Thy1.2- and
B220-enriched cells only displayed a protective effect against $\mathrm{Mtb}$ infection compared with wild-type BMDMs cultured with double-negative-conditioned media. Importantly, conditioned media-co-cultured IFN- $\gamma \mathrm{R}^{-1}$ BMDMs did not show any bacterial-suppressive effects, suggesting that double-positive cell population-derived soluble IFN- $\gamma$ production may play an important role in BMDM bacterial killing effects (Fig. 7C). Collectively, the results indicated that this protection was accompanied by enhanced nitric oxide secretion resulting from Thy $1.2^{+} \mathrm{B} 220^{+}$cell-dependent IFN- $\gamma$ production (Fig. 7B, C, and D). These results indicate that the killing effect of BMDMs against Mtb infection is mediated by IFN- $\gamma$ production by Thy $1.2^{+} \mathrm{B} 220^{+}$ IL-15-DBMCs. 


\section{Discussion}

IL-15 alone and IL-15-primed cells have gained increasing interest because of their therapeutic potential against cancers and infectious diseases. IL-15 is known not only for being involved in developing progenitor cells into DCs $(21,22)$ but also for inducing the proliferation and maintenance of $\mathrm{T}$ cells, ILCs and NK cells (69). In addition, when generating DCs from bone marrow via IL-15 treatment, IL-15-primed DCs have exhibited the ability of producing IFN- $\gamma(13,25)$. Administration of IFN- $\gamma$ is commonly known for reducing the number of bacteria $(67,68)$. In addition, IFN- $\gamma$-producing cells of the myeloid cell lineage were shown to improve the survival rate of infected mice (70). Although IL-15 has been reported to stimulate IFN- $\gamma$ production in myeloid cells, the use of IL-15 in the phenotypic definition of IL-15-DBMCs is still controversial because the phenotypic markers of these cells are occasionally confused with that of pre-mNK cells, NKDCs, IKDCs, and ILC1s.

Therefore, we first investigated and compared the phenotype of IL-15-DBMCs with that of BMDCs. IL-15-DBMCs displayed a higher level of IFN-ץ after LPS treatment (Fig. 1A). Moreover, the population of CD11 $\mathrm{C}^{\text {hiMHC}} \mathrm{MII}{ }^{+}$-matured DCs was reduced, and IL-15-DBMCs instead consisted of more CD11 cint cells, which is considered one of the characteristics of IFN- $\gamma$-producing cells (Fig. 1D and Fig. 2A, B). These data support the concept that IL-15-DBMCs has a distinct phenotype and the association between the CD11 ${ }^{\text {int }}$ population and IFN- $\gamma$ production.

In previous studies, several types of innate cells were reported to have the capacity to produce IFN- $\gamma$, such as IKDCs and ILC1s that include NK cells and immature myeloid cells with ring-shaped nuclei (29). Although NK and T cells were originally reported as major sources of IFN- $\gamma$ production in response to microbial infections, an earlier production of IFN- $\gamma$ by immature myeloid cells than that by NK and T cells and IFN- $\gamma$-producing neutrophils have recently been described $(27,70)$, suggesting both the redundancy in the T cell- and NK cell-mediating IFN- $\gamma$-dependent protection and the contribution of myeloid-derived IFN- $\gamma$-producing innate immune cells in response to infection. Still, the issue of myeloid-derived IFN- $\gamma$ production has been controversial partly because of obscurities in distinguishing the exact source of myeloid cells from NK and T cells (27).

Additionally, when $1 \mu \mathrm{g} / \mathrm{ml}$ of Poly(I:C), known as a stimulator of NK cells, was added to stimulate cells, IFN- $\gamma$ was not detected in either of the two types of cells (Fig. S1B) (71). Moreover, B-, T-, and NK cell-associated surface markers were not related to either BMDCs or IL-15-DBMCs (Fig. S4). IKDCs have been reported to be CD11 $\mathrm{c}^{\mathrm{int}} \mathrm{B} 220^{+} \mathrm{DX} 5^{+}$(or NK1.1 ${ }^{+}$) and Gr-1- $(29,31,34)$. pDCs, a type of DC, are also known to express intermediate levels of CD11c, and Siglec-H and PDCA-1 have been shown to be specific markers for pDCs $(33,72,73)$. IL-15-DBMCs showed refractory expression of specific markers for pDCs (Fig. 2C). Specifically, the $\mathrm{B}_{220^{+}}$population was significantly increased in the IL-15-DBMCs (Fig. 2C), suggesting that IL-15-DBMCs might constitute a different subset of $\mathrm{cDCs}$, pDCs, and NK cells but may be functionally more similar to IKDCs, although these two types of cells do not exhibit the identical phenotype of $\mathrm{CD} 11 \mathrm{C}^{\mathrm{int}} \mathrm{B} 220^{+}$surface markers, except for DX5 and NK1.1. Based on the present study, we hypothesized that $\mathrm{CD} 11 \mathrm{c}^{\mathrm{int}} \mathrm{B} 220^{+}$cells have the capacity of producing IFN- $\gamma$. As expected, this population in IL-15-DBMCs showed increased IFN- $\gamma$ levels (Fig. 3A and B). Although there was a significant difference in level of IFN- $\gamma$ between the B220-depleted population and IL-15-DBMCs, we detected a low level of IFN- $\gamma$ in the B220-depleted population, which was inconsistent with our prediction. This result could be explained by the purity of the cell population, as we used an LS column for cell enrichment (Fig. 5A and Fig. S5A). A previous study showed that $\mathrm{CpG}$ treatment in mice stimulated the expression of IFN- $\gamma$-producing Thy $1.2^{+}$DCs in the spleen (74). Based on our present findings and the reported results, other intriguing phenotypic markers were investigated. Interestingly, we found that Sca-1 and Thy1.2 were significantly increased in IL-15-DBMC-derived CD11 $\mathrm{c}^{\text {intB220 }}{ }^{+}$-enriched cells (Fig. 3C). Our studies are the first to reveal that IL-15-derived CD11 $c^{\text {int }}$ 2220 ${ }^{+}$cells displayed increased levels of both Thy1.2 and Sca-1 expression.

Given that Thy1.2 and Sca-1 have been reported as ILC markers $(41,75)$, we next examined the association of IFN- $\gamma$ production and Thy1.2 and Sca-1 expression in these cells (Fig. 4 and Fig. S5C). Our results clearly point to an increase in the population of IFN- $\gamma$-producing cells gated on target markers. Therefore, IL-15 treatment induces functionally similar ILC1 populations that produce IFN- $\gamma$ and require IL-15 to express Thy1.2 and Sca-1 markers, thus displaying differential expression of CD11c and B220 between ILC1- and IL-15-DBMC-derived IFN- $\gamma$ producing cells (Fig. 5C). Overall, IL-15 treatment during dendritic cell differentiation generates IFN- $\gamma$-producing cells by directing the expansion of cell population (Fig. 6), and these IFN- $\gamma$-producing capacities are characterized by the co-expression of CD11 $\mathrm{c}^{\text {int }} \mathrm{B} 220^{+}$and Thy $1.2^{+}$Sca- $1^{+}$by both IKDC- and ILC1-associated markers. Surprisingly, the

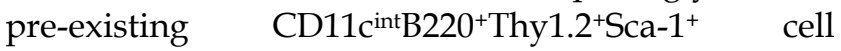
population in freshly isolated bone marrow did not 
produce IFN- $\gamma$ upon LPS stimulation (data not shown), suggesting that IL-15 may induce the expansion of this cell population as well as reprogram the cells that possess IFN- $\gamma$-producing abilities. In addition, the number of this cell population might be not enough for observing IFN- $\gamma$ production, which only constituted $0.03 \%$ of the total bone marrow cells. This observation will be further investigated in our future study. Taken together, the data indicate that IL-15 directly contributes to the expansion of IFN-y-producing IL-15-DBMCs that differ phenotypically from $\mathrm{B}, \mathrm{NK}$, and $\mathrm{T}$ cells by expressing both B220 and Thy1.2 markers.

IFN- $\gamma$ is a principal cytokine involved in both the innate and adaptive immune responses (76), and the capacity to produce IFN- $\gamma$ is considered a protective effect against infections $(70,74)$. In particular, the important role of IL-15 has been reported in the generation of protective immunity and vaccine development as an adjuvant. For example, IL-15 has been shown to protect against Mtb infection in IL-15 transgenic and $\mathrm{KO}$ mice studies and through exogenous IL-15 injection $(77,78)$ by potentiating $\mathrm{T}$ cell proliferation. In addition, IL-15 demonstrated its adjuvant effect in boosting an antigen-specific immune response. For example, IL-15 enhanced the anti-Mtb vaccine efficacy of recombinant BCG by generating durable antigen-specific memory $\mathrm{CD} 4^{+}$ and $\mathrm{CD}^{+} \mathrm{T}$ cells and inducing the production of IFN-Y in response to antigen $85 \mathrm{~B}(79)$. This IL-15-related IFN- $\gamma$ production was found to potentiate the phagocytic function and antimicrobial activity of macrophages and to orchestrate the adaptive immune response through up-regulated antigen presentation in dendritic cells, resulting in enforced T cell immune responses $(80,81)$.

In the present study, co-culturing Mtb-infected murine BMDMs with sorted IFN- $\gamma$-producing IL-15-DBMCs prevented bacterial growth. This result is in line with previous studies showing the immunoprotective activity of IFN- $\gamma$-producing cells (74). Interestingly, suppressive activity of BMDMs co-cultured with IFN- $\gamma$-producing IL-15-DBMCs in bacterial growth is superior to that of BMDMs treated with recombinant IFN- $\gamma$ alone, indicating that another factor may be involved in this killing activity other than the increased $\mathrm{NO}$ production. However, as one possible explanation or mechanism, we clearly demonstrated that protection against Mtb infection was controlled by IFN- $\gamma$ production by Thy1.2+B220+-IL-15-DBMCs (Fig. 7B, C and D). Thus, further investigations into the mechanism involved in the killing effect of IFN- $\gamma$-producing IL-15-DBMCs on Mtb infection are required to clarify whether this cell type can be used in the treatment of TB-infected patients. Taken together, the prompt initiation of IFN- $\gamma$-activated mechanisms in infected macrophages could be beneficial in eliminating Mtb infection before the bacteria actively propagate inside the host.

Obviously, our present study has several limitations that require further investigation. First, the exact origin of this IFN- $\gamma$-producing IL-15-DBMC population should be determined to define the associated cell lineage. Recently, Belyaev et al. identified the emergence of an atypical progenitor subset with both lymphoid and myeloid potential in Plasmodium chabaudi-infected mice (82). Thus, understanding how the progenitor compartments respond to environmental and pathophysiological conditions will define key mechanisms for the selective regulation of differentiation and proliferation of IFN- $\gamma$-producing IL-15-DBMCs. Second, IFN- $\gamma$-producing IL-15-DBMCs can play a key role in the immediate protection against $\mathrm{Mtb}$ infection in vivo prior to the initiation of the Th1 immune response. We are currently investigating whether this cell type exists in vivo after IL-15 injection with various TLR agonists. Obviously, whether phenotypically similar IL-15-DBMCs exist in humans for the purpose of future clinical applications should be determined. Moreover, this investigation could be strengthened by using single-cell RNA-sequencing to identify novel cell subsets (83). Additionally, we are currently investigating the applications of IFN- $\gamma$-producing IL-15-DBMCs in Mtb treatment and vaccine development by enforcing the innate immune responses via the transfer of IFN- $\gamma$-producing IL-15-DBMCs into mice susceptible to Mtb infection, which are highly susceptible due to delayed IFN- $\gamma$ responses. These limitations have also been associated with endless controversies in terms of identifying cell subsets, especially between IKDCs and NK cells, because of phenotypical obscurities. Based on developmental and functional overlaps, IKDCs have been regarded as one of the subsets of NK cells $(56,84,85)$. Although IFN- $\gamma$-producing IL-15-DBMCs also displayed overlapping surface markers, these generated cells are different given that CD11 $c^{\text {intB220 }}{ }^{+}$cells do not express NK1.1 and CD49b cells display the exact same pattern as generated BMDCs (Fig. 2C and Fig. S3). In addition, IFN- $\gamma$-producing IL-15-DBMCs did not respond to the NK cell agonist, Poly(I:C) (Fig. S1B). However, the cell lineages or progenitors that are regulated upon IL-15 treatment should be addressed in our next study since hematopoiesis occurs in bone marrow (86). Although,

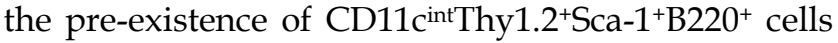
were identified in freshly isolated bone marrow, it will be further investigated whether IL-15 directed 
expansion of this cell population or even influenced differentiation of bone marrow cell progenitors apart from pre-existing cell population. This study will facilitate the identification of cell subsets more clearly, even in in vivo experiments with IL-15-injected mice to overcome our limitations. Nevertheless, to the best of our knowledge, our study revealed for the first time that IL-15 drives the expansion of IFN- $\gamma$-producing CD11 $c^{\text {intB } 220+}$ Thy $1.2^{+}$Sca- $1^{+}$from bone marrow in a GM-CSF-dependent manner; moreover, this cell subset co-expresses lymphoid-myeloid lineage phenotypic markers and shows therapeutic potential against Mtb infection in the in vitro macrophage system.

In conclusion, IFN- $\gamma$-producing IL-15-DBMCs

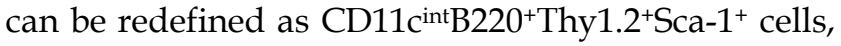
which phenotypically resemble both IKDCs or pre-mNK and ILC1s, and could be a therapeutic potential to control intracellular Mtb growth inside macrophages by potentiating the IFN- $\gamma-\mathrm{NO}$ axis. The current challenges are to further investigate the development of IFN- $\gamma$-producing IL-15-DBMCs into ILC1s and IKDCs or pre-mNK cells and to identify the origin, the existence, and the human counterpart of this cell type.

\section{Abbreviations}

APC: allophycocyanin; BFA: brefeldin A; BM: bone marrow; BMDCs: bone marrow-derived dendritic cells; BMDMs: bone marrow-derived macrophages; $\mathrm{CD}$ : cluster of differentiation; $\mathrm{CFU}$ : colony-forming unit; DCs: dendritic cells; DPBS: Dulbecco's PBS; ELISA: enzyme-linked immunosorbent assay; FITC: fluorescein isothiocyanate; GM-CSF: granulocyte macrophage colony-stimulating factor; ICS: intracellular staining; IFN- $\gamma$ : interferon gamma; IKDCs: interferonproducing killer dendritic cells; ILC: innate lymphoid cell; ILC1: type 1 innate lymphoid cell; ILC2: type 2 innate lymphoid cell; ILC3: type 3 innate lymphoid cell; IL-15: interleukin-15; IL-15-DBMCs: IL-15-differentiated bone marrow-derived cells; LPS: lipopolysaccharide; MACS: magnetic activated cell sorting; Mtb: Mycobacterium tuberculosis; NK: natural killer; NKDCs: natural killer dendritic cells; NO: nitric oxide; OADC: oleic acid-albumin-dextrose-catalase; ODN: CpG oligonucleotide; Pam3CSK4: N-palmitoylS-dipalmitoylglyceryl Cys-Ser-(Lys) ${ }_{4} ;$ pDCs: plasmacytoid dendritic cells; PE: phycoerythrin; PerCP: peridinin chlorophyll; Poly(I:C): polyinosinicpolycytidylic acid; Pre-mNK: premature NK; TLR: toll-like receptor; TNF: tumor necrosis factor.

\section{Supplementary Materials}

Supplementary figures.

http://www.ijbs.com/v15p0464s1.pdf

\section{Acknowledgments}

This research was supported by the Basic Science Research Program through the National Research Foundation of Korea (NRF) funded by the Ministry of Science, ICT \& Future Planning (NRF-2016R1A2A1A05005263) and the Global Research Laboratory (GRL) Program of the NRF funded by the Ministry of Science, ICT \& Future Planning (2016K1A1A2910779). The authors would also like to thank Professor Sang-Jun Ha from the College of Life Science and Biotechnology, Department of Biochemistry, Yonsei University, for his helpful advice on the experimental design and technical support.

\section{Authorship}

KWK and SJK designed and performed the experiments, analyzed the data, and wrote the manuscript. WSK, HK, KWK, SMK and EC performed the experiments and contributed to the interpretation of the results. SJK and KWK contributed to the discussion of the results and to writing the paper. SJS conceived the study and supervised the team. SJS and SJH designed the experiments. SJS and JHY critically revised the manuscript. All authors participated in the preparation and editing of the manuscript.

\section{Competing Interests}

The authors have declared that no competing interest exists.

\section{References}

1. Patidar M, Yadav N, Dalai SK. Interleukin 15: A key cytokine for immunotherapy. Cytokine Growth Factor Rev. 2016;31:49-59.

2. Fehniger TA, Caligiuri MA. Interleukin 15: biology and relevance to human disease. Blood. 2001;97(1):14-32

3. Ali AK, Nandagopal N, Lee SH. IL-15-PI3K-AKT-mTOR: A Critical Pathway in the Life Journey of Natural Killer Cells. Front Immunol. 2015;6:355.

4. Cheever MA. Twelve immunotherapy drugs that could cure cancers. Immunol Rev. 2008;222:357-68.

5. Kutzler MA, Robinson TM, Chattergoon MA, Choo DK, Choo AY, Choe PY, et al. Coimmunization with an optimized IL-15 plasmid results in enhanced function and longevity of CD8 T cells that are partially independent of CD4 T cell help. J Immunol. 2005;175(1):112-23.

6. Mueller YM, Bojczuk PM, Halstead ES, Kim AH, Witek J, Altman JD, et al. IL-15 enhances survival and function of HIV-specific CD8+ T cells. Blood. 2003;101(3):1024-9.

7. Perera PY, Lichy JH, Waldmann TA, Perera LP. The role of interleukin-15 in inflammation and immune responses to infection: implications for its therapeutic use. Microbes Infect. 2012;14(3):247-61.

8. Yajima T, Nishimura H, Ishimitsu R, Watase T, Busch DH, Pamer EG, et al. Overexpression of IL-15 in vivo increases antigen-driven memory CD8+ T cells following a microbe exposure. J Immunol. 2002;168(3):1198-203.

9. Alpdogan O, Eng JM, Muriglan SJ, Willis LM, Hubbard VM, Tjoe KH, et al. Interleukin-15 enhances immune reconstitution after allogeneic bone marrow transplantation. Blood. 2005;105(2):865-73.

10. Sun A, Wei H, Sun R, Xiao W, Yang Y, Tian Z. Human interleukin-15 improves engraftment of human $\mathrm{T}$ cells in NOD-SCID mice. Clin Vaccine Immunol. 2006;13(2):227-34.

11. Brandt K, Bulfone-Paus S, Foster DC, Ruckert R. Interleukin-21 inhibits dendritic cell activation and maturation. Blood. 2003;102(12):4090-8. 
12. Steinman RM. The dendritic cell system and its role in immunogenicity. Annu Rev Immunol. 1991;9:271-96.

13. Anguille S, Smits EL, Cools N, Goossens H, Berneman ZN, Van Tendeloo VF. Short-term cultured, interleukin-15 differentiated dendritic cells have potent immunostimulatory properties. J Transl Med. 2009;7:109.

14. Steinman RM, Banchereau J. Taking dendritic cells into medicine. Nature. 2007:449(7161):419-26.

15. Reichardt VL, Brossart P, Kanz L. Dendritic cells in vaccination therapies of human malignant disease. Blood Rev. 2004;18(4):235-43.

16. Dauer M, Obermaier B, Herten J, Haerle C, Pohl K, Rothenfusser S, et al. Mature dendritic cells derived from human monocytes within 48 hours: a novel strategy for dendritic cell differentiation from blood precursors. J Immunol. 2003;170(8):4069-76.

17. Dauer M, Schad K, Herten J, Junkmann J, Bauer C, Kiefl R, et al. FastDC derived from human monocytes within $48 \mathrm{~h}$ effectively prime tumor antigen-specific cytotoxic T cells. J Immunol Methods. 2005;302(1-2):145-55.

18. Tawab A, Fan Y, Read EJ, Kurlander RJ. Effect of ex vivo culture duration on phenotype and cytokine production by mature dendritic cells derived from peripheral blood monocytes. Transfusion. 2009;49(3):536-47.

19. Jarnjak-Jankovic S, Hammerstad H, Saeboe-Larssen S, Kvalheim G, Gaudernack G. A full scale comparative study of methods for generation of functional Dendritic cells for use as cancer vaccines. BMC Cancer. 2007;7:119.

20. Tanaka F, Yamaguchi $H$, Haraguchi $N$, Mashino $K$, Ohta $M$, Inoue $H$, et al. Efficient induction of specific cytotoxic $\mathrm{T}$ lymphocytes to tumor rejection peptide using functional matured 2 day-cultured dendritic cells derived from human monocytes. Int J Oncol. 2006;29(5):1263-8

21. Mohamadzadeh M, Berard F, Essert G, Chalouni C, Pulendran B, Davoust J, et al. Interleukin 15 skews monocyte differentiation into dendritic cells with features of Langerhans cells. J Exp Med. 2001;194(7):1013-20.

22. Feau S, Facchinetti V, Granucci F, Citterio S, Jarrossay D, Seresini S, et al. Dendritic cell-derived IL-2 production is regulated by IL-15 in humans and in mice. Blood. 2005;105(2):697-702.

23. Harris KM. Monocytes differentiated with GM-CSF and IL-15 initiate Th17 and Th1 responses that are contact-dependent and mediated by IL-15. J Leukoc Biol. 2011;90(4):727-34.

24. Feili-Hariri M, Falkner DH, Morel PA. Polarization of naive T cells into Th1 or Th2 by distinct cytokine-driven murine dendritic cell populations: implications for immunotherapy. J Leukoc Biol. 2005;78(3):656-64.

25. Okada S, Han S, Patel ES, Yang LJ, Chang LJ. STAT3 signaling contributes to the high effector activities of interleukin-15-derived dendritic cells. Immunol Cell Biol. 2015;93(5):461-71.

26. Kraaij MD, Vereyken EJ, Leenen PJ, van den Bosch TP, Rezaee F, Betjes MG, et al. Human monocytes produce interferon-gamma upon stimulation with LPS. Cytokine. 2014;67(1):7-12.

27. Sturge CR, Benson A, Raetz M, Wilhelm CL, Mirpuri J, Vitetta ES, et al. TLR-independent neutrophil-derived IFN-gamma is important for host resistance to intracellular pathogens. Proc Natl Acad Sci U S A. 2013;110(26):10711-6.

28. Bogdan C, Schleicher U. Production of interferon-gamma by myeloid cells--fact or fancy? Trends Immunol. 2006;27(6):282-90.

29. Chan CW, Crafton E, Fan HN, Flook J, Yoshimura K, Skarica M, et al. Interferon-producing killer dendritic cells provide a link between innate and adaptive immunity. Nat Med. 2006;12(2):207-13.

30. Bonmort $M$, Ullrich E, Mignot $G$, Jacobs B, Chaput N, Zitvogel L. Interferon-gamma is produced by another player of innate immune responses: the interferon-producing killer dendritic cell (IKDC). Biochimie. 2007;89(6-7):872-7.

31. Taieb J, Chaput N, Menard C, Apetoh L, Ullrich E, Bonmort M, et al. A novel dendritic cell subset involved in tumor immunosurveillance. Nat Med. 2006;12(2):214-9

32. Ullrich E, Bonmort M, Mignot G, Jacobs B, Bosisio D, Sozzani S, et al. Trans-presentation of IL-15 dictates IFN-producing killer dendritic cells effector functions. J Immunol. 2008;180(12):7887-97.

33. Himoudi N, Nabarro S, Buddle J, Eddaoudi A, Thrasher AJ, Anderson J. Bone marrow-derived IFN-producing killer dendritic cells account for the tumoricidal activity of unpulsed dendritic cells. J Immunol. 2008;181(9):6654-63.

34. Guimont-Desrochers F, Cappello ZJ, Chagnon M, McDuffie M, Lesage S. Cutting edge: genetic characterization of IFN-producing killer dendritic cells. J Immunol. 2009;182(9):5193-7.

35. Terme M, Mignot G, Ullrich E, Bonmort M, Minard-Colin V, Jacquet A, et al. The dendritic cell-like functions of IFN-producing killer dendritic cells reside in the $\mathrm{CD} 11 \mathrm{~b}+$ subset and are licensed by tumor cells. Cancer Res. 2009;69(16):6590-7

36. Guimont-Desrochers F, Lesage S. Revisiting the Prominent Anti-Tumoral Potential of Pre-mNK Cells. Front Immunol. 2013:4:446.

37. Welner RS, Pelayo R, Garrett KP, Chen X, Perry SS, Sun XH, et al. Interferon-producing killer dendritic cells (IKDCs) arise via a unique differentiation pathway from primitive c-kitHiCD62L+ lymphoid progenitors. Blood. 2007;109(11):4825-931.

38. Robbins SH, Walzer T, Dembele D, Thibault C, Defays A, Bessou G, et al. Novel insights into the relationships between dendritic cell subsets in human and mouse revealed by genome-wide expression profiling. Genome Biol. 2008;9(1):R17.
39. Guimont-Desrochers F, Boucher G, Dong Z, Dupuis M, Veillette A, Lesage S. Redefining interferon-producing killer dendritic cells as a novel intermediate in NK-cell differentiation. Blood. 2012;119(19):4349-57.

40. Zitvogel L, Housseau F. IKDCs or B220+ NK cells are pre-mNK cells. Blood. 2012;119(19):4345-6.

41. Artis D, Spits H. The biology of innate lymphoid cells. Nature. 2015;517(7534):293-301.

42. Jiao Y, Huntington ND, Belz GT, Seillet C. Type 1 Innate Lymphoid Cell Biology: Lessons Learnt from Natural Killer Cells. Front Immunol. 2016;7:426.

43. Gasteiger G, Fan X, Dikiy S, Lee SY, Rudensky AY. Tissue residency of innate lymphoid cells in lymphoid and nonlymphoid organs. Science. 2015;350(6263):981-5

44. Bernink JH, Peters CP, Munneke M, te Velde AA, Meijer SL, Weijer K, et al. Human type 1 innate lymphoid cells accumulate in inflamed mucosal tissues. Nat Immunol. 2013;14(3):221-9.

45. Daussy C, Faure F, Mayol K, Viel S, Gasteiger G, Charrier E, et al. T-bet and Eomes instruct the development of two distinct natural killer cell lineages in the liver and in the bone marrow. J Exp Med. 2014;211(3):563-77.

46. Fuchs A, Vermi W, Lee JS, Lonardi S, Gilfillan S, Newberry RD, et al. Intraepithelial type 1 innate lymphoid cells are a unique subset of IL-12- and IL-15-responsive IFN-gamma-producing cells. Immunity. 2013;38(4):769-81.

47. Klose CSN, Flach M, Mohle L, Rogell L, Hoyler T, Ebert K, et al. Differentiation of type 1 ILCs from a common progenitor to all helper-like innate lymphoid cell lineages. Cell. 2014;157(2):340-56.

48. Diefenbach A, Colonna M, Koyasu S. Development, differentiation, and diversity of innate lymphoid cells. Immunity. 2014;41(3):354-65.

49. Kennedy MK, Glaccum M, Brown SN, Butz EA, Viney JL, Embers M, et al. Reversible defects in natural killer and memory CD8 T cell lineages in interleukin 15-deficient mice. J Exp Med. 2000;191(5):771-80.

50. Burkett PR, Koka R, Chien M, Chai S, Boone DL, Ma A. Coordinate expression and trans presentation of interleukin (IL)-15Ralpha and IL-15 supports natural killer cell and memory CD8+ $\mathrm{T}$ cell homeostasis. J Exp Med. 2004;200(7):825-34.

51. Schuster IS, Wikstrom ME, Brizard G, Coudert JD, Estcourt MJ, Manzur M, et al. TRAIL+ NK cells control CD4+ T cell responses during chronic viral infection to limit autoimmunity. Immunity. 2014;41(4):646-56.

52. Bezman NA, Kim CC, Sun JC, Min-Oo G, Hendricks DW, Kamimura Y, et al. Molecular definition of the identity and activation of natural killer cells. Nat Immunol. 2012;13(10):1000-9.

53. Toe JG, Pellegrini M, Mak TW. Promoting immunity during chronic infection--the therapeutic potential of common gamma-chain cytokines. Mol Immunol. 2013;56(1-2):38-47.

54. Kim WS, Kim JS, Cha SB, Kim H, Kwon KW, Kim SJ, et al. Mycobacterium tuberculosis Rv3628 drives Th1-type T cell immunity via TLR2-mediated activation of dendritic cells and displays vaccine potential against the hyper-virulent Beijing K strain. Oncotarget. 2016;7(18):24962-82.

55. Segura E, Wong J, Villadangos JA. Cutting edge: B220+CCR9- dendritic cells are not plasmacytoid dendritic cells but are precursors of conventional dendritic cells. J Immunol. 2009;183(3):1514-7.

56. Vosshenrich CA, Lesjean-Pottier S, Hasan M, Richard-Le Goff O, Corcuff E, Mandelboim O, et al. CD11cloB220+ interferon-producing killer dendritic cells are activated natural killer cells. J Exp Med. 2007;204(11):2569-78.

57. Spits H, Artis D, Colonna M, Diefenbach A, Di Santo JP, Eberl G, et al. Innate lymphoid cells--a proposal for uniform nomenclature. Nat Rev Immunol. 2013;13(2):145-9.

58. Walker JA, Barlow JL, McKenzie AN. Innate lymphoid cells--how did we miss them? Nat Rev Immunol. 2013;13(2):75-87.

59. Taube C, Tertilt C, Gyulveszi G, Dehzad N, Kreymborg K, Schneeweiss K, et al. IL-22 is produced by innate lymphoid cells and limits inflammation in allergic airway disease. PLoS One. 2011;6(7):e21799.

60. Flynn JL, Chan J, Triebold KJ, Dalton DK, Stewart TA, Bloom BR. An essential role for interferon gamma in resistance to Mycobacterium tuberculosis infection. J Exp Med. 1993;178(6):2249-54

61. Boom WH, Wallis RS, Chervenak KA. Human Mycobacterium tuberculosis-reactive CD4+ T-cell clones: heterogeneity in antigen recognition, cytokine production, and cytotoxicity for mononuclear phagocytes. Infect Immun. 1991;59(8):2737-43.

62. Del Prete GF, De Carli M, Mastromauro C, Biagiotti R, Macchia D, Falagiani P, et al. Purified protein derivative of Mycobacterium tuberculosis and excretory-secretory antigen(s) of Toxocara canis expand in vitro human $\mathrm{T}$ cells with stable and opposite (type $1 \mathrm{~T}$ helper or type $2 \mathrm{~T}$ helper) profile of cytokine production. J Clin Invest. 1991;88(1):346-50.

63. Orme IM, Roberts AD, Griffin JP, Abrams JS. Cytokine secretion by CD4 T lymphocytes acquired in response to Mycobacterium tuberculosis infection. J Immunol. 1993;151(1):518-25.

64. Chen K, Kolls JK. T cell-mediated host immune defenses in the lung. Annu Rev Immunol. 2013;31:605-33.

65. Orme IM, Robinson RT, Cooper AM. The balance between protective and pathogenic immune responses in the TB-infected lung. Nat Immunol. 2015;16(1):57-63

66. Pathak SK, Basu S, Basu KK, Banerjee A, Pathak S, Bhattacharyya A, et al. Corrigendum: Direct extracellular interaction between the early secreted antigen ESAT-6 of Mycobacterium tuberculosis and TLR2 inhibits TLR signaling in macrophages. Nat Immunol. 2015;16(3):326 
67. Hanano R, Kaufmann SH. Nitric oxide production and mycobacterial growth inhibition by murine alveolar macrophages: the sequence of rIFN-gamma stimulation and Mycobacterium bovis BCG infection determines macrophage activation. Immunol Lett. 1995;45(1-2):23-7.

68. Herbst S, Schaible UE, Schneider BE. Interferon gamma activated macrophages kill mycobacteria by nitric oxide induced apoptosis. PLoS One. 2011;6(5):e19105.

69. Gaston DC, Odom CI, Li L, Markert JM, Roth JC, Cassady KA, et al. Production of bioactive soluble interleukin-15 in complex with interleukin-15 receptor alpha from a conditionally-replicating oncolytic HSV-1. PLoS One. 2013;8(11):e81768

70. Matsumura T, Ato M, Ikebe T, Ohnishi M, Watanabe H, Kobayashi K. Interferon-gamma-producing immature myeloid cells confer protection against severe invasive group A Streptococcus infections. Nat Commun. 2012;3:678.

71. McCartney S, Vermi W, Gilfillan S, Cella M, Murphy TL, Schreiber RD, et al. Distinct and complementary functions of MDA5 and TLR3 in poly(I:C)-mediated activation of mouse NK cells. J Exp Med. 2009;206(13):2967-76.

72. Blasius AL, Giurisato E, Cella M, Schreiber RD, Shaw AS, Colonna M. Bone marrow stromal cell antigen 2 is a specific marker of type I IFN-producing cells in the naive mouse, but a promiscuous cell surface antigen following IFN stimulation. J Immunol. 2006;177(5):3260-5.

73. Blasius AL, Cella M, Maldonado J, Takai T, Colonna M. Siglec-H is an IPC-specific receptor that modulates type I IFN secretion through DAP12. Blood. 2006;107(6):2474-6.

74. Ishii KJ, Ito S, Tamura T, Hemmi H, Conover J, Ozato K, et al. CpG-activated Thy1.2+ dendritic cells protect against lethal Listeria monocytogenes infection. Eur J Immunol. 2005;35(8):2397-405.

75. Mair F, Becher B. Thy1+ Sca1+ innate lymphoid cells infiltrate the CNS during autoimmune inflammation, but do not contribute to disease development. Eur J Immunol. 2014;44(1):37-45.

76. Schroder K, Hertzog PJ, Ravasi T, Hume DA. Interferon-gamma: an overview of signals, mechanisms and functions. J Leukoc Biol. 2004;75(2):163-89.

77. Rausch A, Hessmann M, Holscher A, Schreiber T, Bulfone-Paus S, Ehlers S, et al. Interleukin-15 mediates protection against experimental tuberculosis: a role for NKG2D-dependent effector mechanisms of CD8+ T cells. Eur J Immunol. 2006;36(5):1156-67.

78. Pydi SS, Bandaru AR, Venkatasubramanian S, Jonnalagada S, Valluri VL. Vaccine for tuberculosis: up-regulation of IL-15 by Ag85A and not by ESAT-6. Tuberculosis (Edinb). 2011:91(2):136-9.

79. Tang C, Yamada H, Shibata K, Maeda N, Yoshida S, Wajjwalku W, et al. Efficacy of recombinant bacille Calmette-Guerin vaccine secreting interleukin-15/antigen 85B fusion protein in providing protection against Mycobacterium tuberculosis. J Infect Dis. 2008;197(9):1263-74.

80. Lee SH, Miyagi T, Biron CA. Keeping NK cells in highly regulated antiviral warfare. Trends Immunol. 2007;28(6):252-9.

81. Degli-Esposti MA, Smyth MJ. Close encounters of different kinds: dendritic cells and NK cells take centre stage. Nat Rev Immunol. 2005;5(2):112-24.

82. Belyaev NN, Brown DE, Diaz AI, Rae A, Jarra W, Thompson J, et al. Induction of an IL7-R(+)c-Kit(hi) myelolymphoid progenitor critically dependent on IFN-gamma signaling during acute malaria. Nat Immunol. 2010;11(6):477-85.

83. Villani AC, Satija R, Reynolds G, Sarkizova S, Shekhar K, Fletcher J, et al. Single-cell RNA-seq reveals new types of human blood dendritic cells, monocytes, and progenitors. Science. 2017;356(6335).

84. Caminschi I, Ahmet F, Heger K, Brady J, Nutt SL, Vremec D, et al. Putative IKDCs are functionally and developmentally similar to natural killer cells, but not to dendritic cells. J Exp Med. 2007;204(11):2579-90.

85. Blasius AL, Barchet W, Cella M, Colonna M. Development and function of murine B220+CD11c+NK1.1+ cells identify them as a subset of NK cells. J Exp Med. 2007;204(11):2561-8.

86. Kaufmann E, Sanz J, Dunn JL, Khan N, Mendonca LE, Pacis A, et al. BCG Educates Hematopoietic Stem Cells to Generate Protective Innate Immunity against Tuberculosis. Cell. 2018;172(1-2):176-90.e19. 